\title{
LA ESCUELA DE HIJOS DE OBREROS DE MINAS DE ALMADÉN. UN EJEMPLO DE ENSEÑANZA MANJONIANA
}

\author{
The School Children of Mining Workers of Almaden. An example \\ of manjonian teaching
}

\section{Emiliano Almansa Rodríguez ${ }^{\alpha}$ y Ángel Hernández Sobrino ${ }^{\beta}$}

Fecha de recepción: 13/05/2019 • Fecha de aceptación: 09/03/2020

Resumen: Las Escuelas del Ave María fueron fundadas en Granada, año 1889, por el sacerdote y pedagogo Andrés Manjón. A diferencia del método tradicional de enseñanza infantil en aquellos años, el padre Manjón centraba su pedagogía en la religión católica, considerando la naturaleza como obra de Dios. En su concepto, el juego, los trabajos manuales y la enseñanza al aire libre formaban buenos cristianos en un ambiente alegre para que se incorporasen posteriormente al mundo laboral. Extendidas rápidamente por España y otros países, las Escuelas del Ave María están consideradas una experiencia pionera de la enseñanza en su época y gozaron de un gran prestigio social.

En el subsuelo de Almadén se explotó desde la dominación árabe el yacimiento de mercurio más grande del mundo, en el que trabajaban en la primera mitad del siglo XX unos 2.500 operarios. La Escuela de Hijos de Obreros había sido fundada en 1908, pero en 1926, coincidiendo con la proclamación de la dictadura de Primo de Rivera, se transformó en una escuela manjoniana. Convertida en escuela laica durante la Segunda República y la posterior guerra civil, volvió a actuar como escuela del Ave María desde 1939 hasta la década de 1960. Minas de Almadén, al igual que otras grandes empresas mineras e industriales del norte de España, ejerció una estrategia paternalista con sus operarios y eligió la

\footnotetext{
${ }^{\alpha}$ Escuela de Ingeniería Minera e Industrial (Universidad de Castilla-La Mancha). Plaza Manuel Meca, s/n. 13400 Almadén (Ciudad Real). España. emiliano.almansa@uclm.es (D) https://orcid.org/00000003-3918-5308.

B Escuela de Ingeniería Minera e Industrial (Universidad de Castilla-La Mancha). Urbanización Solana del Cristo, 11. 13400 Almadén (Ciudad Real). España. ahsobrino@gmail.com (D) https://orcid. org/0000-0002-3059-4378
}

Cómo citar este artículo: Almansa Rodríguez, Emiliano y Ángel Hernández Sobrino. «La escuela de hijos de obreros de minas de Almadén. Un ejemplo de enseñanza manjoniana». Historia y Memoria de la Educación 13 (2021): 455-502 
enseñanza religiosa como la más adecuada para la formación de sus hijos.

Palabras clave: Minas de Almadén; paternalismo industrial; padre Manjón; Escuela Hijos de Obreros.

Abstract: Ave Maria Schools were founded in Granada in 1889 by the priest and educator Andrés Manjón. Unlike the traditional method of infant education in those years, Father Manjón centered pedagogy in the Catholic religion, considering nature as God's work. In his concept, play, manual labor and outdoor teaching were good Christians in a happy environment so that they would later join the working world. They quickly spread throughout Spain and other countries, Ave Maria Schools are considered a pioneering experience of teaching in their time and enjoyed great social prestige.

In the subsoil of Almadén, the largest mercury deposit in the world was exploited from the Arab domination, with 2,500 workers working in the first half of the 20th century. The School of Children of Workers had been founded in 1908, but in 1926, coinciding with the proclamation of the dictatorship of Primo de Rivera, it was transformed into a Manjonian school. Become a secular school during the Second Republic and the subsequent civil war, he returned to act as a school of Ave Maria from 1939 until the 1960s. Minas de Almadén, like other large mining and industrial companies in northern Spain, exercised a paternalistic strategy with its operators and chose religious education as the most appropriate for the formation of their children.

Keywords: Almaden mines, industrial paternalism, father Manjon, Children of Workers School.

A principios del siglo XX, la educación no constituía un bien generalizado en la sociedad española y la tasa de alfabetización era de solo un 44\%, mientras que en Gran Bretaña alcanzaba el 97\% y en Francia el $83 \%$. Las dificultades presupuestarias del siglo XIX no habían permitido construir un sistema escolar nacional, de modo que los gastos de educación primaria correspondían a los municipios, los cuales también andaban siempre escasos de recursos económicos. A principios del siglo XX, todas las escuelas de enseñanza primaria tenían un solo maestro o maestra, quien daba clase a alumnos de cinco a trece años, clasificando a los mismos en secciones y grados. ${ }^{1}$

\footnotetext{
1 Antonio Viñao Frago, Escuela para todos. Educación y modernidad en la España del siglo XX (Madrid: Marcial Pons Historia, 2004), 25.
} 
Otra causa de la baja escolarización en España fue el mercado laboral infantil, aunque la ley de 24 de junio de 1873 estableció la prohibición de trabajar a los menores de diez años en industrias, talleres, fundiciones y minas, y la limitación a cinco horas de la jornada laboral de niños menores de trece años y niñas menores de catorce. Patronos y obreros miraban con buenos ojos el trabajo infantil, ya que los primeros se veían favorecidos por los bajos salarios que abonaban a los niños y los segundos porque con el trabajo de sus hijos complementaban el presupuesto familiar en una época de carestía y alto coste de la vida. ${ }^{2}$

Una de las industrias más significativas del mercado laboral, en cuanto al trabajo infantil se refiere, fue la minería que, junto a la agricultura, se convirtió en la actividad que más niños empleó hasta la década de 1920.3 Almadén es un buen exponente de trabajo infantil, ya que los propios mineros eran los primeros interesados en conseguir un puesto de trabajo para sus hijos, pues les aseguraba su futuro laboral, aunque corriera peligro su salud al realizar trabajos peligrosos e insalubres. ${ }^{4} \mathrm{El}$ empleo de mano de obra infantil en Almadén fue habitual en las labores subterráneas y en los hornos metalúrgicos, hasta que en 1906 se prohibió que trabajaran en el establecimiento minero los menores de 16 años. ${ }^{5}$

Entretanto, las nuevas ideas pedagógicas que estaban en pleno desarrollo en Europa se querían implantar en España, de modo que la enseñanza no fuera memorística sino razonada, que los alumnos estuvieran en contacto frecuente con la naturaleza y que la relación entre profesores y alumnos fuera mayor, así como la de aquellos con las familias de estos. ${ }^{6}$

\footnotetext{
2 Alejandro Tiana Ferrer, «Educación obligatoria, asistencia escolar y trabajo infantil en España en el primer tercio del siglo XX», Historia de la educación 6 (1987): 47. http://campus.usal.es/ revistas_trabajo/index.php/0212-0267/article/viewFile/6735/6725.

3 Miguel Ángel Pérez de Perceval y Andrés Sánchez Picón, «El trabajo infantil en la minería española, 1850-1940 », VIII Congreso de la Asociación Española de Historia Económica, Santiago de Compostela, 2005.

4 Ángel Hernández Sobrino, Los mineros del azogue (Ciudad Real: Fundación Almadén-Francisco Javier de Villegas, 2007), 309.

${ }_{5}^{5}$ Luis Mansilla Plaza y Ana Isabel Gallego-Preciados Algora, «El trabajo infantil en las Minas de Almadén desde el siglo XVIII hasta 1939», II Congreso Nacional de Ciudad Real y su Provincia, Ciudad Real, Instituto de Estudios Manchegos, 2016, 547.

${ }_{6}^{6}$ Francisco Javier Pericacho Gómez, «Pasado y presente de la renovación pedagógica de España (de finales del Siglo XIX a nuestros días). Un recorrido a través de escuelas emblemáticas», Revista Complutense de Educación 25, n. ${ }^{\circ} 1$ (2014): 49-51. http://dx.doi.org/10.5209/rev_RCED.2014.v25.n1.43309.
} 
Una nueva corriente regeneradora y educativa, el «krausismo», se enfrentó en una batalla frontal con los neocatólicos. Frente al catolicismo, que según los krausistas solo había traído hipocresía, intolerancia y decadencia, ellos propusieron la desamortización de la fe, la exaltación de una conciencia personal, la perfección individual y colectiva, y el cumplimiento de derechos y deberes cívicos. ${ }^{7}$ Su proyecto de Escuela Nueva era una enseñanza laica, de espiritualidad íntima y amante de la naturaleza, en definitiva, una educación activa, integral, armónica, gradual, coeducativa y laica. ${ }^{8}$

El objetivo primordial de este artículo es el estudio de la Escuela de Hijos de Obreros de Minas de Almadén en los periodos de enseñanza manjoniana, es decir, de 1926 a 1931 y de 1939 a 1959 . No obstante, y para dar continuidad a la historia educativa de este importante enclave minero, se contempla también la época anterior a 1926 y el periodo de 1931 a 1939. Tanto cuando se impuso la Dictadura de Primo de Rivera como cuando lo hizo la de Franco, el Consejo de Administración de Minas de Almadén, que dependía del Ministerio de Hacienda y que comenzó a funcionar en 1918, vio el momento oportuno para implantar la enseñanza avemariana en la citada escuela. Este modelo fue frecuente en los grandes centros industriales y mineros de finales del siglo XIX y primera mitad del XX, pues se trataba de que los hijos de los obreros se encontraran en condiciones de recibir, además de la educación necesaria, un conjunto de preceptos religiosos y morales para convertirse en el futuro en competentes y dóciles operarios. ${ }^{9}$ En cuanto a las niñas cuya sección fue creada en 1928 e independiente de las de los niños, sin olvidar tampoco su educación primaria, aprendían cocina, corte y confección, y otras materias, cuyo objetivo era la administración de su futuro hogar, a fin de que «... resplandezca el orden, la economía y la higiene necesaria, y su compañero encuentre más comodidad y agrado que en las tabernas y casinos». ${ }^{10}$

\footnotetext{
${ }^{7}$ Ricardo García Cárcel, La herencia del pasado. Las memorias históricas de España (Barcelona: Galaxia Gutenberg, 2011), 438-439.

8 Pericacho Gómez, «Pasado y presente..., 47-67.

9 Por ejemplo, las Escuelas de Hullera Española y las de Unión Hullera y Metalúrgica de Asturias estaban dirigidas por los Hermanos de la Doctrina Cristiana, mientras que la de Industrial Asturiana seguía el modelo manjoniano.

10 Sisinio Nevares, El patrono ejemplar. Una obra maestra de acción social (Madrid: Editorial Razón y Fe, 1936), 62.
} 
La Escuela de Hijos de Obreros es un buen ejemplo de las prácticas paternalistas que las grandes empresas del norte de España ejercieron sobre sus operarios. Mediante este sistema, los patronos capitalistas no solo intervenían en el trabajo de los operarios sino también en sus vidas. Viviendas, economatos, escuelas e iglesias son algunas de las pautas que utilizaron para conseguir productores eficaces y responsables. En Almadén, pese a tratarse de una mina del Estado, también sucedió así, especialmente en dos épocas, durante la dictadura de Primo de Rivera y durante la de Franco, como demostraremos en este artículo.

La Escuela de Hijos de Obreros, fundada por una Real Orden en 1908, jugó un importante papel en la enseñanza de la infancia en la villa minera desde entonces. Convertida en escuela manjoniana durante la dictadura de Primo de Rivera, volvió a ser una escuela laica durante la república y guerra civil, cuando las enseñanzas del padre Manjón fueron abandonadas y sus maestros perseguidos. Después de la guerra, los perseguidos fueron los maestros republicanos, mientras que los manjonianos volvieron a sus puestos de trabajo y la escuela retornó de nuevo a los principios de enseñanza avemariana, si bien influida por los principios del nacional catolicismo. En la década de 1950 se produjo en la enseñanza una transición gradual del totalitarismo nacional y católico a la tecnocracia autoritaria, de modo que los rasgos del periodo precedente de posguerra y autarquía se suavizaron. Poco a poco se fue aminorando el patriotismo y el adoctrinamiento político, cambiando a una educación menos dogmática. No obstante, la enseñanza continuó siendo confesional y la asignatura de religión siguió presente en todos los niveles educativos. ${ }^{11}$

Las fuentes primarias de investigación son las casi cuatrocientas cincuenta actas del Consejo de Administración de Minas de Almadén y Arrayanes, correspondientes al periodo de 1918 a 1959, que se guardan en el Archivo Histórico de Minas de Almadén, excepto las correspondientes a los años de la guerra civil, que están en el Archivo Histórico

\footnotetext{
11 En 1951 fue nombrado ministro de Educación, Joaquín Ruiz Giménez, miembro de la Asociación Católica Nacional de Propagandistas. Los cursillos de cristiandad organizados por Acción Católica fueron frecuentes en esa década y en Almadén también los hubo de hombres y mujeres, eso sí, por separado.
} 
Nacional, sede de Madrid. ${ }^{12}$ La memoria escolar de algunos cursos de las décadas de 1940 y 1950 se conserva también en el citado archivo de Almadén. En cuanto al deplorable estado de la enseñanza infantil en Almadén anterior a la creación de la Escuela de Hijos de Obreros, existen datos en los libros de José María Pontes y Fernández, y de Desiderio Marín Rodríguez. De mayor interés es el libro de Ana Isabel Gallego-Preciados Algora (coordinadora), que comprende desde la fundación de la citada escuela hasta el año 2008, si bien es fundamentalmente descriptivo y no explica los motivos de elección de la enseñanza manjoniana. Las fuentes secundarias utilizadas para contextualizar el artículo han sido las siguientes: sobre las escuelas del Ave María, los artículos de Francisco Canes Garrido y Victorino de Arce, quienes analizan esta institución, y también algunos textos que aparecen en los propios libros del padre Manjón. Como ejemplos de otras escuelas avemarianas en pueblos mineros, las aportaciones de E. García López y M. Arbizu Senosiaín sobre la escuela de Arnao (Asturias) y de Francisco Asensio Rubio sobre la de Puertollano (Ciudad Real), la primera de ellas mucho más importante y duradera que la segunda. Además, el último autor estudia la enseñanza primaria en la provincia de Ciudad Real durante la Segunda República y la guerra civil, si bien hay pocos datos de Almadén. Respecto a la enseñanza en general en España, el libro de Antonio Viñao, que describe el proceso de acceso de los españoles a la educación en el siglo XX. También son de interés el libro de Ricardo García Cárcel, en especial su texto sobre el krausismo, y el artículo de Javier Pericacho Gómez, donde compara las diversas corrientes educativas de finales del siglo XIX. Para la primera mitad del siglo XX, debemos citar los artículos de Juan Manuel Fernández Soria, quien denuncia el olvido planificado de la educación republicana durante el franquismo; de Damián A. González Madrid, sobre la década de 1940; de Ramón Navarro Saladrinas y su relato sobre las dificultades de la enseñanza durante el franquismo; y los libros de Rafael Valls Montés y de Jaime Vicens Vives y Jaime Sobrequés. Además, para la depuración de los maestros en Castilla-La Mancha (1936-1945), es fundamental la tesis doctoral de Sara Ramos Zamora, quien pone de manifiesto con datos exhaustivos la doble purga

\footnotetext{
12 A diferencia de la documentación de Minas de Almadén correspondiente a los siglos XVI al XIX, que fue trasladada de Almadén al Archivo Histórico Nacional, la correspondiente al siglo XX se conserva en su mayor parte en el Archivo Histórico de Minas de Almadén.
} 
republicana y franquista que sufrieron los enseñantes. Por último, sobre la historia de los mineros de Almadén en el siglo XX, dos de los libros de Ángel Hernández Sobrino, uno que trata de los mineros de Almadén en general, y otro de los reclusos mineros de la posguerra, este último en colaboración con Javier Vinagre Moreno.

\section{LAS ESCUELAS DEL AVE MARÍA}

Algunas escuelas católicas también renovaron sus métodos en esa época de cambio del siglo XIX al XX. Las más innovadoras fueron las del Ave María, fundadas por Andrés Manjón, un sacerdote burgalés, para educar gratuitamente a los niños pobres, muchos de ellos gitanos, que vivían en el Sacromonte, uno de los barrios de las afueras de Granada. La primera Escuela del Ave María tuvo su sede en los sótanos de la abadía del Sacromonte y empezó a funcionar en 1889 con 14 niñas. ${ }^{13} \mathrm{El}$ número de alumnos creció rápidamente y en el curso 1895-1896 ya había 1.431 , repartidos en 12 clases y distribuidos por edades y sexos. ${ }^{14} \mathrm{La}$ enseñanza impartida era integral, dedicada tanto al intelecto infantil como a las actividades al aire libre, pero sus ideas no se separaban un ápice de las otras escuelas católicas, convirtiéndose por tanto en un elemento a favor de la iglesia y en contra del liberalismo. ${ }^{15}$

Frente a esta corriente pedagógica estaba la krausista, la cual tenía muchos puntos en común con la manjoniana, ya que también sostenía el contacto con la naturaleza, la enseñanza al aire libre, el papel activo del maestro, la enseñanza práctica, etc., si bien existía una diferencia nítida, pues mientras la manjoniana defendía la instrucción religiosa, la krausista era laica. ${ }^{16}$ Ante esta tesitura, los grandes empresas eligieron la enseñanza católica, avemariana o no, frente a la krausista, seguramente porque esperaban que de esta manera los futuros obreros serían más dóciles y obedientes, y también más resignados ante las adversidades. A medida que los conflictos obreros fueron ganando en amplitud e intensidad en

\footnotetext{
13 Francisco Canes Garrido, «Las Escuelas del Ave María: una institución renovadora de finales del siglo XIX en España», Revista Complutense de Educación 10, n. ${ }^{\circ} 2$ (1999): 152. http://revistas.ucm.es/ index.php/RCED/article/view/RCED9999220149A/17151.

${ }_{14}$ Canes, «Las Escuelas del Ave María: una institución renovadora...», 152

15 Victorino de Arce, «Manjón, educador», Pulso (2002): 91.

16 Arce, «Manjón, educador», 97.
} 
las primeras décadas del siglo XX, la preferencia por las escuelas religiosas se fue incrementando, de modo que los patronos deseaban que en cada centro minero o industrial importante hubiera una escuela, donde a los hijos de los obreros se les inculcase ideas religiosas como freno moral. En Almadén, aunque todas las corrientes se reflejaban con un cierto retraso debido a su lejanía y aislamiento, las protestas y huelgas convocadas por la Federación Local Obrera habían aumentado considerablemente a partir de 1919, por lo que el primer Consejo de Administración nombrado después del golpe de Estado de Primo de Rivera eligió también la enseñanza manjoniana como la más adecuada para los hijos de los mineros.

A principios del XX, nuevas escuelas y campamentos escolares fueron fundados en otros barrios y en el extrarradio de Granada. Además, en 1905, se instaló en el Carmen de la Victoria el seminario para la formación de maestros del Ave María. ${ }^{17}$ Superando las expectativas de su fundador, las escuelas del padre Manjón se extendieron por toda España y otros países del entorno, sobrepasando el número de 300 las que llevaban su nombre en 1920 y triplicando esta cifra las que seguían sus métodos y procedimientos. ${ }^{18}$ Una de las más queridas por el padre Manjón fue la de Sargentes de Lora (Burgos), su pueblo natal. Otras escuelas se crearon en pueblos mineros, como fueron las de Almadén y Puertollano (Ciudad Real), y varias más en Asturias, entre ellas, la de Arnao. Esta última fue fundada en 1913 por la Real Compañía Asturiana de Minas, una empresa privada que promovía el paternalismo y la filantropía desde el sector empresarial. La escuela formaba parte de otras prestaciones sociales, como viviendas, economato y hospital. ${ }^{19}$

Construida en plena naturaleza, la escuela de Arnao era el lugar apropiado para desarrollar plenamente los principios educativos de la pedagogía manjoniana, pues los niños, además de literatura y geometría, estudiaban el entorno natural, las rocas, las plantas y los animales.

\footnotetext{
17 Andrés Manjón Manjón, Hojas circunstanciales, hojas históricas y hojas cronológicas del Ave María (Madrid: Gráficas Nebrija, 1956), 423-424.

18 En casi todas las capitales de provincia españolas había una o varias escuelas manjonianas, mientras que en Asturias superaban la media docena.

19 María Esther García López y Miguel Arbizu Senosiaín, «La escuela manjoniana del Ave María de Arnao. Su pasado: un siglo de historia», en Actas del XIV Congreso de la SEDPGYM, comp. José María Mata Perelló (Manresa: SEDPGYM, 2014), 670.
} 
Sus instalaciones fueron consideradas las mejor dotadas de Asturias, mientras que las escuelas públicas disponían de edificios escolares inadecuados a sus fines y, además, antihigiénicos. En el contexto social de Asturias del principio del siglo XX eran frecuentes estas iniciativas filantrópicas del sector empresarial, las cuales paliaban el deficiente panorama social, suplantando así las competencias que la Administración tenía asignadas, pero que nunca podía abordar por falta de presupuesto. ${ }^{20}$

Otro ejemplo de estos proyectos educativos es el de Hullera Española, una empresa de carbón asturiana que costeaba cuatro escuelas en 1911 con un total de 1.000 alumnos. En 1936, las escuelas eran ya siete y en ellas recibían enseñanza más de 3.000 alumnos menores de catorce años, con separación de niños y niñas. Otras empresas asturianas que también tenían escuelas fueron Unión Hullera y Metalúrgica, Fábrica de Mieres e Industrial Asturiana. ${ }^{21}$ En 1911, el ingeniero y geólogo Lucas Mallada, interesado también en temas políticos y sociales, afirmaba que:

[...] en lo que respecta a la enseñanza, este es un dato verdaderamente consolador, pues abre la esperanza de que en un plazo no muy lejano, las condiciones morales y sociales del país habrán de mejorar mucho más que lo que empeoraron en estos veinte últimos años, con motivo de las agitaciones provocadas por los elementos rebeldes que nunca faltan entre el proletariado. ${ }^{22}$

No todas las escuelas avemarianas existentes en España eran tan grandes como la de Arnao o la de Almadén, como lo demuestra la existente en Puertollano, una escuela que debió empezar en 1924 con la llegada al poder de Primo de Rivera. En 1927 y con el objetivo de mejorar el funcionamiento de la misma fue destinado a ella otro sacerdote avemariano, al parecer sobrino del padre Manjón. ${ }^{23}$ En los años de la República se puso en marcha el Patronato de la escuela y esta llegó a contar

\footnotetext{
${ }^{20}$ García y Arbizu, «La escuela manjoniana del Ave María de Arnao...», 672.

21 Dirección General de Agricultura, Minas y Montes. Informe relativo al estado económico y situación social de los obreros de las Minas y Fábricas metalúrgicas de España y organismos de protección instituidos en beneficio de los mismos (Madrid, 1911), 48-53.

22 Dirección General de Agricultura, Minas y Montes. Informe relativo al estado económico y situación social de los obreros de las Minas..., 48.

${ }_{23}$ Francisco Asensio Rubio, La enseñanza primaria. Ciudad Real: II República y Guerra civil (Ciudad Real: Excma. Diputación Provincial de Ciudad Real, 2007), 236-237.
} 
con seis grupos y 300 alumnos, pero en 1936 los grupos se habían reducido a dos y el número de alumnos a 100. El triunfo del Frente Popular supuso el principio del fin de la enseñanza manjoniana en Puertollano y en junio de dicho año se incautó el edificio de la escuela al prohibirse la enseñanza religiosa. ${ }^{24}$

El padre Andrés Manjón definía la pedagogía como «la ciencia y el arte de educar e instruir al hombre, esto es, un conjunto de principios científicos y reglas prácticas, cuyo objeto final es hacer hombres cabales y completos, tal cual Dios los quiere y la sociedad los necesita». ${ }^{25}$ Para el padre Manjón, la educación que se daba a los niños españoles en aquellos años era deficiente porque en todo caso instruía pero no educaba. Para él la práctica educativa debía enseñar y formar hombres y mujeres, bien desarrollados, sanos de cuerpo y alma, y «... dignos del fin para el que han sido creados y de la sociedad a la que pertenecen».26 La diferencia fundamental entre esta enseñanza y la pública era su impronta activa e intuitiva, una enseñanza al aire libre, en permanente contacto con la naturaleza, en la que los niños disfrutaban de un ambiente sano y saludable. En resumen y desde la perspectiva católica, el padre Manjón fue uno de los introductores en nuestro país del activismo pedagógico. ${ }^{27}$

\section{LA ESCUELA DE HIJOS DE OBREROS DESDE SU FUNDACIÓN EN 1908 HASTA 1931}

Al igual que en otros distritos mineros españoles, en Almadén venía siendo habitual que niños y muchachos trabajaran en el interior de la mina y en los hornos de tostación del mineral. Esta situación venía heredada de siglos atrás, pero todavía a mediados del siglo XIX los mineros de Almadén, obligados por la necesidad de obtener ingresos suplementarios para garantizar la subsistencia familiar, intentaban introducir a sus

\footnotetext{
${ }^{24}$ Asensio, La enseñanza primaria..., 239.

25 Andrés Manjón Manjón, Discurso leído en la solemne apertura del Curso Académico 1897-1898 en la Universidad Literaria de Granada (Granada: Imprenta-Escuela del Ave María, 1905), 5.

26 Manjón, Discurso leído en la solemne apertura del Curso Académico 1897-1898..., 3.

27 Para exaltar la obra del padre Manjón se rodó en 1943 la película Forja de almas, frecuentemente proyectada en las escuelas durante la posguerra.
} 
hijos cuanto antes en los trabajos del establecimiento minero. ${ }^{28}$ Los niños acudían así a la mina en lugar de ir a la escuela, lo que, no por necesario, era menos pernicioso. En palabras del ingeniero Fernando García Arenal, haciendo referencia a este problema en Asturias, año 1885:

El empleo de los chicos desde los 11 y 12 años, como viene haciéndose, es de lo más perjudicial que imaginarse pueda para su desarrollo y su cultura intelectual. El primero se verifica de un modo incompleto, estando en general dedicados a trabajos superiores a sus fuerzas y por lo mismo antihigiénicos; así es característico el aspecto de todos estos desgraciados que a los 16 años parece que tienen 13 y aún menos respecto a fuerza y vigor, y veinte en cuanto a vicios y aires hombrunos. ${ }^{29}$

En la década de 1840, dejando aparte la Academia de Capataces de Minas, había en Almadén una escuela de primera enseñanza superior, cuyo maestro cobraba de los fondos públicos 4.000 reales anuales, otra escuela pública elemental y tres escuelas de niñas, cada una con la asignación de 1.000 reales anuales. ${ }^{30}$ Mientras los niños estudiaban religión, aritmética, lengua castellana y otras materias, las niñas aprendían «... labores propias de su sexo, leer y doctrina cristiana».31 A finales de la centuria de 1800 ya existían dos escuelas públicas elementales de niños, dos de niñas y una de párvulos, dotadas con 1.100 pesetas cada una. La matrícula total ascendía por entonces a 1.249 alumnos y la asistencia media no superaba el $55 \%$, aunque «... sería más numerosa si las necesidades de las familias pobres no les obligaran a retirar a sus hijos antes de tiempo para dedicarlos a algún trabajo, de remuneración siempre escasa».32 Para la segunda enseñanza existía un colegio particular con una matrícula de unos 20 alumnos, quienes iban a examinarse a los institutos de Badajoz y Ciudad Real.

\footnotetext{
${ }^{28}$ Hernández, Los mineros del azogue, 307.

${ }_{29}$ Fernando García Arenal, Datos para el estudio de la cuestión social (Gijón: Imprenta del comercio, 1885), 309.

30 Pascual Madoz, Diccionario geográfico-estadístico-histórico de España y sus posesiones de ultramar, 1845-1850 (Madrid: Ámbito Editorial, 1987), tomo II, 18.

${ }_{31}$ Madoz, Diccionario geográfico-estadístico-histórico de España. Almadén era en aquellos años un pujante pueblo minero con 8.500 habitantes.

32 José María Pontes y Fernández, Historia de la antigua ciudad de Sisapón (hoy Almadén del Azogue) (Madrid: Imprenta de Enrique Rojas, 1900), 46-47.
} 
La primera escuela de adultos en Almadén fue fundada en 1856 por José María Ugarte, superintendente de la mina, secundada por Jerónimo Quintana, alcalde de Almadén, y regida por Gregorio Lillo, maestro e hijo de Almadén. A esta escuela llegaron a acudir hasta un millar de personas con edades comprendidas entre los diez y veinticuatro años. Además se preparó otro local para los operarios de la mina con edades comprendidas entre los veinticinco y cuarenta años. La calidad de la enseñanza impartida era elevada y así lo manifiesta un alumno, Fernando Lozano, ${ }^{33}$ al fallecimiento de Gregorio Lillo, ocurrido en 1894:

D. Gregorio Lillo, mi maestro amado, mi maestro venerado, fue un iluminado, un apóstol del saber. ¿Cuál es la última palabra de la pedagogía moderna? La enseñanza integral, esa enseñanza que su insigne inventor, nuestro honorable amigo Mr. Sluys ${ }^{34}$ propaga desde la dirección del magisterio belga, una enseñanza que, por otros caminos, ha puesto en práctica nuestra Institución Libre de Enseñanza. Pues bien, esa misma enseñanza, en los límites que le permitía su cultura, sin base filosófica, la practicaba ya en su escuela hace más de cuarenta años D. Gregorio Lillo. ${ }^{35}$

Lamentablemente, a los sucesores del superintendente Ugarte parece que les importaba poco que los obreros supieran leer y escribir, lo que supuso menor ayuda económica del establecimiento minero a la enseñanza. Además, cada vez se hacía más evidente que el Ayuntamiento de Almadén no disponía de fondos suficientes para la dotación de las escuelas y la remuneración de los profesores, por lo que la única solución era que Minas de Almadén se hiciera cargo del asunto. Al fin y al cabo, Almadén era un pueblo que vivía desde hacía siglos de y para la mina.

En 1906, Desiderio Marín y Rodríguez, capataz facultativo, llamó la atención del director del establecimiento minero y del alcalde de

\footnotetext{
${ }_{33}$ Nacido en Almadenejos, localidad cercana a Almadén, Fernando Lozano Montes fue director del semanario Las Dominicales del Libre Pensamiento, donde firmaba con el seudónimo de «Demófilo». Los redactores de este semanario se definían a sí mismos como «...una divertida ensalada ideológica de deístas, anticlericales, masones y republicanos».

${ }_{34}$ Alexis Sluys fue nombrado director de la Escuela Modelo de Bruselas en 1878, institución que dirigió durante treinta años.

35 Fernando Lozano Montes, «Mi maestro», Las Dominicales del Libre Pensamiento (Madrid), 15 de junio de 1894.
} 
Almadén sobre la conveniencia de fomentar la enseñanza, sobre todo teniendo en cuenta la existencia de locales adecuados en el establecimiento minero sin ninguna utilización y la disposición de maestros y capataces para dedicarse a tan noble labor. ${ }^{36}$ Desiderio Marín también incidió en la utilidad pública de implantar una Escuela de Artes y Oficios, «... para la cual fuera pequeño el sacrificio que hicieran el Estado y el Municipio, teniendo en cuenta los elementos con que el establecimiento minero cuenta, tanto en material, locales, talleres, etc., cuanto en personal que pudiera auxiliar al profesorado».37 Esta solicitud no cayó en saco roto, ya que Waldo Ferrer, a la sazón administrador general de Minas de Almadén, envió en noviembre de 1906 una petición a las autoridades municipales, donde exponía «... la necesidad de crear un centro educativo práctico, en donde los hijos de los obreros puedan adquirir el amor al trabajo y a las artes, creando con ello una nueva escuela de cultura, de respeto y de obediencia».38

Una Real Orden de 6 de marzo de 1908 autorizó la construcción de la Escuela de Hijos de Obreros con su biblioteca y gimnasio, y el lugar elegido fue el solar de la antigua factoría de bueyes y mulas de la Real Hacienda, ya que dichos animales habían sido sustituidos casi totalmente por la energía de vapor. El principal objetivo del Ministerio de Hacienda al crear dicha escuela era el mejoramiento físico-intelectual de los hijos de los mineros, completando sus conocimientos y creando estímulos de buena conducta, laboriosidad y amor al trabajo, considerándose las clases de religión y moral solamente como un complemento al plan general. El éxito fue completo, pues ya en el primer curso hubo 350 alumnos, de los que 50 eran adultos que asistían a clases nocturnas, y el resto, hijos de los operarios de la mina y de comerciantes, artesanos y campesinos de Almadén. La enseñanza tenía un marcado carácter religioso y se basaba en la memorización y en la disciplina, no interesándose en otras cuestiones pedagógicas o sociales. En 1910 se añadió a las asignaturas habituales de letras y ciencias la clase de música como una opción no obligatoria.

\footnotetext{
36 Desiderio Marín y Rodríguez, Almadén y sus obreros (Ciudad Real: Establecimiento tipográfico de Enrique Pérez, 1906), 26.

37 Marín, Almadén y sus obreros, 27.

38 Ana Isabel Gallego-Preciados Algora (coord.), Colegio Hijos de Obreros de Almadén. La huella de un siglo (Albacete: Gráficas Campollano, 2008), 13.
} 
Ya en 1906 se creó el batallón infantil escolar y se celebró la fiesta del árbol y de los pájaros a propuesta de una serie de vecinos de Almadén preocupados por la escasez de árboles, «... siendo los propios niños los que con sus manos los planten y cuiden en los días que esta fiesta se celebre...».39 También había que terminar con la afición a cazar pájaros, la cual debía ser severamente castigada, ya que los pájaros «... limpian de insectos y malas semillas los campos y en todos los países civilizados se cuida de su propagación y cría...». ${ }^{40}$ Se complementaba así el plan educativo de la escuela recién creada, de modo que:

[...] el batallón infantil escolar tiene que ser en lo sucesivo el escudo que ampare y defienda los árboles de los paseos y calles, llegando con la creación de la Fiesta del Árbol a convertir en frondoso vergel aquellos sitios del centro y de las afueras de la población que hoy nos denuncian al viajero como un pueblo incivil y refractario al progreso. ${ }^{41}$

Al comienzo del siglo XX, el establecimiento minero de Almadén se regía por una reglamentación laboral implantada por el Ministerio de Hacienda en 1865. Debido al azogamiento producido por el vapor de mercurio, los operarios que trabajaban en las labores subterráneas daban ocho jornales mensuales de seis horas de duración cada uno y por cada tres meses de trabajo en el interior de la mina tenían derecho a ser destinados al exterior durante un mes. Aun así, nadie estaba contento con la situación: los mineros y los incipientes gremios sindicales porque los salarios eran bajos y el Estado porque se trabajaba poco. El ingeniero Rafael Souvirón, quien era en 1904 director interino de la mina, definía así la situación en un informe elevado a la superioridad: «Domina sobre toda la organización actual un antagonismo latente entre la Hacienda, defendiendo lo que entiende ser de su interés, y la mayor parte de los obreros, que considerándose mal retribuidos, escatiman buena voluntad y energías en el desempeño de su cometido».42

\footnotetext{
${ }^{39}$ Gallego-Preciados, Colegio Hijos de Obreros de Almadén..., 62.

40 Gallego-Preciados, Colegio Hijos de Obreros de Almadén..., 63.

${ }^{41}$ Gallego-Preciados, Colegio Hijos de Obreros de Almadén..., 63.

42 Rafael Souvirón del Río, Primer informe a la Dirección General y presupuesto para 1905, Archivo Histórico Nacional (AHN), Fondos Contemporáneos-Minas Almadén (FC-MA), legajo 1556, caja 6, 27 de febrero de 1904, p. 2.
} 
A pesar de que se enviaron dos comisiones oficiales a Almadén, una del Ministerio de Fomento en 1906 y otra del Instituto de Reformas Sociales en 1910, la situación no mejoró, por lo que el Ministerio de Hacienda decidió crear en 1916 el Consejo de Administración de Minas de Almadén y Arrayanes, si bien el Real Decreto no se dictó hasta el 25 de junio de $1918 .{ }^{43}$ Una de las peticiones realizada en 1910 por la Sociedad de Barreneros de Almadén al Instituto de Reformas Sociales fue precisamente «... que se reclame al Estado cumpla con los deberes de protección para sus obreros, ilustrándoles con escuelas dirigidas por profesores aptos y con la construcción de talleres en donde obtengan los jóvenes la enseñanza necesaria para llegar a ser obreros inteligentes y cultos». ${ }^{44}$ A partir de 1918, el funcionamiento de la Escuela de Hijos de Obreros se reguló por el Reglamento de Escuelas Graduadas, lo que implicó cambios profundos en la distribución y usos del espacio y del tiempo escolares. ${ }^{45}$

A comienzos de la década de 1920, los gremios sindicales incrementaron sus quejas y denuncias y promovieron diversas huelgas y manifestaciones. Entretanto, la Escuela de Hijos de Obreros había entrado en una época de atonía, así que el Consejo de Administración encomendó a Alfonso Retortillo y Tornos, catedrático de la Escuela Superior de Magisterio de Madrid, la realización de un estudio sobre la organización idónea de la citada escuela. El estudio debía abarcar las mejoras que habían de introducirse en su gestión, los materiales de enseñanza más apropiados, los maestros que debían ejercer la enseñanza (había algunos que eran empleados de la mina sin la titulación adecuada) y su nombramiento de acuerdo con las disposiciones vigentes, y si era conveniente ampliar la enseñanza a los adultos, dado el estado cultural del personal obrero. ${ }^{46}$

El golpe de Estado del general Primo de Rivera truncó este plan, pues el Consejo de Administración fue cesado casi en pleno, nombrando

\footnotetext{
43 Arrayanes es el nombre de una mina de plomo, sita en Linares (Jaén), que también pertenecía al Estado y era administrada, al igual que Almadén, por el Ministerio de Hacienda.

${ }^{44}$ Gallego-Preciados, Colegio Hijos de Obreros de Almadén..., 24.

45 Gallego-Preciados, Colegio Hijos de Obreros de Almadén..., 25.

${ }_{46}$ Archivo Histórico de Minas de Almadén (AHMA), Actas del Consejo de Administración (ACA), 21 de septiembre de 1923, 1.
} 
nuevo presidente del mismo a Antonio del Castillo, almirante de la Armada. Después de lidiar con los muchos y graves problemas técnicos y de seguridad e higiene en el trabajo del establecimiento minero, el Consejo empezó a mejorar las instalaciones de la escuela, las cuales estaban en un estado lamentable, en especial las aulas de párvulos, que hubieron de ser clausuradas temporalmente. ${ }^{47}$ Por otra parte, el Consejo decidió que los hijos de los obreros recibiesen una educación religiosa como freno moral a la sociedad en la que vivían. Por ello, entregó la enseñanza de la escuela a maestros avemarianos, dirigiéndose al obispo auxiliar de Granada, quien ejercía como director de las Escuelas del Ave María, pues el padre Manjón ya había fallecido. ${ }^{48}$ Los dos primeros maestros avemarianos llegaron a Almadén en enero de 1926 y pronto se notó que no había buena armonía entre los maestros nacionales y los recién llegados, así que el Consejo decidió separar las aulas de unos y de otros. ${ }^{49}$ Por otra parte, el Consejo amplió en 1928 las escuelas de niñas y niños, además de realizar las obras necesarias para que fueran independientes sus locales y para higienizar las instalaciones. ${ }^{50} \mathrm{El}$ aumento del alumnado elevó la plantilla de maestros a cinco y, además, se hizo una inversión de 10.500 pesetas en obras, mobiliario y enseres, lo que unido a los sueldos de los maestros, 4.000 pesetas anuales, duplicó el presupuesto de la Escuela. Por tanto, no es de extrañar que cuando D. Pedro Manjón, director de las Escuelas del Ave María, visitó Almadén, elogiara «las instalaciones de la Escuela de Hijos de Obreros, calificándolas como una de las mejores que tienen en España».51 Por todo ello, la Escuela se convirtió en el mayor gasto social del Consejo, ya que al Economato se le obligó a partir de 1928 a vender los artículos a un precio que cubriera su coste. ${ }^{52}$

Aunque había tres clases de niños y dos de niñas, todavía quedaban en Almadén muchos niños sin escolarizar, por lo que el Consejo creó tres nuevas secciones a finales de 1930, dos de niños y una de niñas. El número de alumnos alcanzó casi los 300. Un año antes el Consejo había

\footnotetext{
47 AHMA, ACA, 17 de agosto de 1925, 3-4.

48 AHMA, ACA, 25 de octubre de 1925, 3-4.

49 AHMA, ACA, 1 de marzo de 1926, 8-9.

50 AHMA, ACA, 2 de marzo de 1928, 7.

51 AHMA, ACA, 15 de julio de 1929, 5.

52 AHMA, ACA, 22 de junio de 1928, 5.
} 
nombrado director a Don Escolástico González Izquierdo, «... el profesor más caracterizado de dichas escuelas». ${ }^{53}$

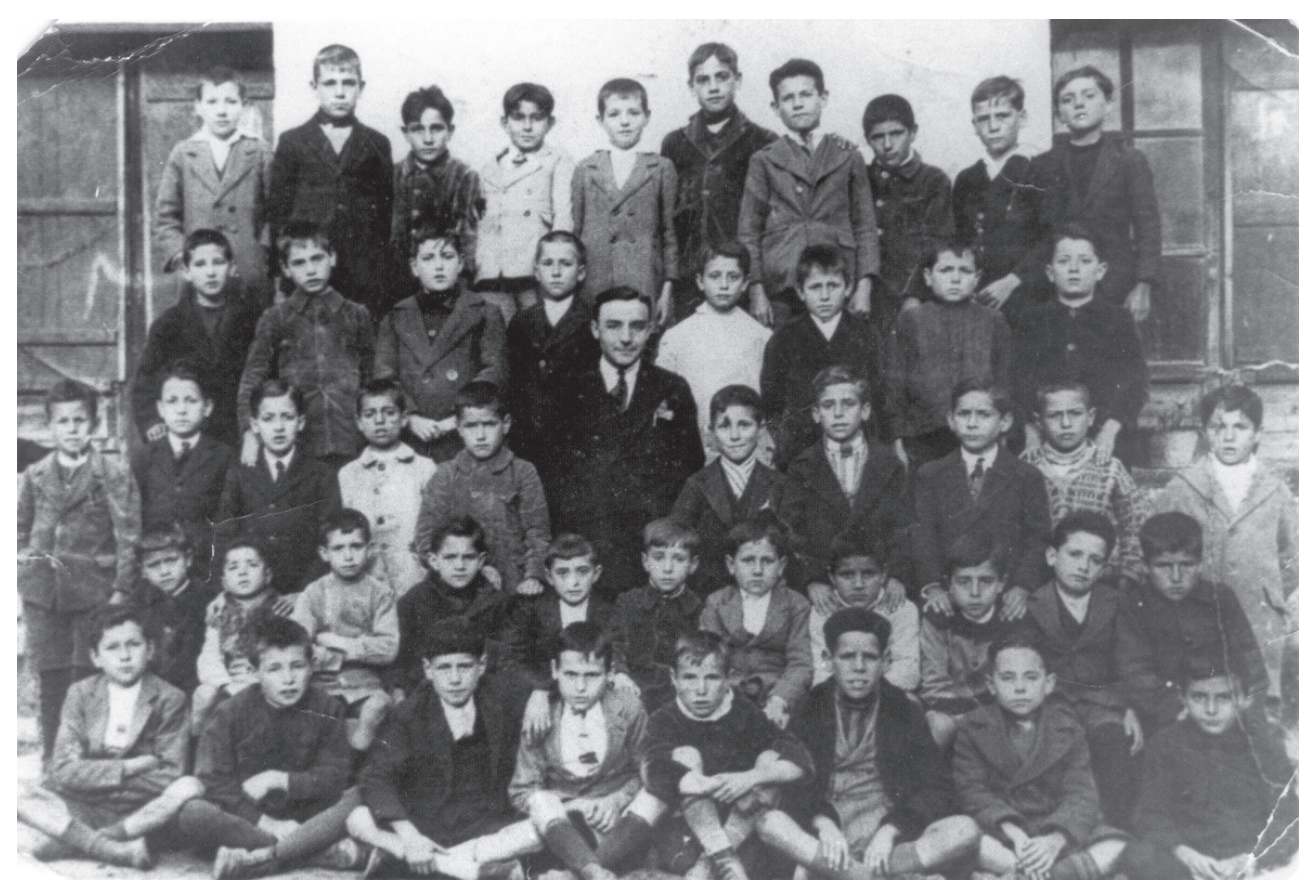

Imagen 1. D. Escolástico con sus alumnos hacia 1930. Fuente: mipuebloalmaden.blogspot.com

Además de las mejoras realizadas en el recinto de la antigua factoría, como la creación de una superficie arbolada que daba abundante sombra, el Consejo decidió ampliar las becas y ayudas de estudio, concediendo una beca anual para que el alumno más aventajado pudiera estudiar una carrera no superior a cuatro años fuera de Almadén. La beca tenía una dotación anual de 1.650 pesetas y también se crearon ocho premios anuales de 50 pesetas cada uno para aquellos alumnos de cada curso que terminaran sus estudios con mayor aprovechamiento. ${ }^{54}$

A pesar del hundimiento de la Bolsa de Nueva York en 1929 y del descenso consiguiente de la cotización de los metales, incluido el mercurio, Minas

\footnotetext{
53 AHMA, ACA, 20 de noviembre de 1929, 7.

54 AHMA, ACA, 22 de diciembre de 1930, 10-14.
} 
de Almadén continuó las ventas a través del cártel que había formado en 1928 con Italia, el otro gran productor mundial. ${ }^{55}$ Por ello, la Escuela de Hijos de Obreros continuaba sus expectativas de crecimiento del alumnado y mejora de las instalaciones en esa época. Entre 1924 y 1930, la situación de la enseñanza en España mejoró progresivamente, creando numerosas escuelas y aumentando el personal docente, lo que trajo consigo la reducción del hacinamiento escolar. La labor de la dictadura de Primo de Rivera en el campo educativo quedó reflejada en la tasa de analfabetismo, de modo que en Almadén disminuyó del 64,62\% en $1920^{56}$ al 48,94 en 1930 (41,56\% en hombres y 55,88\% en mujeres). ${ }^{57}$ En el conjunto de la provincia de Ciudad Real descendió entre 1924 y 1930 del $67,52 \%$ al 55,64\%.58

\section{LA ÉPOCA DE LA REPÚBLICA Y GUERRA CIVIL (1931-1939)}

La Segunda República prestó mucha atención a la educación y puso en funcionamiento muchas escuelas nuevas y un extenso programa de actuaciones que afectaban a la selección de los maestros, a la sustitución de la enseñanza religiosa por la laica, al plan de estudios y a la mejora de instituciones, como las cantinas, los roperos o las colonias escolares. Ya en 1931 se había decretado la gratuidad y obligatoriedad de la enseñanza primaria, la libertad de cátedra y la laicidad de la enseñanza en general, de modo que la asignatura de religión dejó de ser obligatoria, «existiendo libertad absoluta en la instrucción religiosa para alumnos de ambos sexos». ${ }^{59}$ No obstante, se reconoció a las iglesias (católica, evangélica u otras) el derecho a enseñar sus respectivas doctrinas en sus colegios, pero siempre bajo la inspección del Estado. El proyecto educativo de construir 27.000 nuevas escuelas y dotar 10.000 nuevas plazas de maestro en toda España solo se pudo cumplir parcialmente por falta de medios de muchos ayuntamientos, entre otros el de Almadén. ${ }^{60}$

\footnotetext{
55 Hernández, Los mineros del azogue, 412.

56 Asensio, La enseñanza primaria..., 64.

57 Asensio, La enseñanza primaria..., 66.

58 Francisco Alía Miranda, Ciudad Real durante la dictadura de Primo de Rivera (Ciudad Real: Instituto de Estudios Manchegos, 1986), 137.

59 Decreto de 6 de mayo de 1931.

${ }^{60} \mathrm{El}$ canon anual de unas 30.000 pesetas que el Consejo abonaba al Ayuntamiento sobre el producto bruto del mineral era minúsculo, si lo comparamos con los millones de pesetas que ingresaba año
} 
En Almadén, aunque se inició una campaña para convertir la Escuela de Hijos de Obreros en una escuela pública, el Consejo intentó mantener siempre su criterio, pues al fin y al cabo era quien la costeaba. El primer problema vino como consecuencia de que en Almadén había todavía muchos hijos de mineros sin escolarizar, mientras que había algunos alumnos de la escuela que eran hijos de autoridades locales y empleados del Estado y del Ayuntamiento, lo que dio lugar a diversas quejas y denuncias. La situación mejoró con el traslado de la Escuela de Capataces de Minas a su antigua sede, la Academia de Minas, lo que permitió disponer de dos nuevas aulas, una para 50 niños y otra mixta para 80 párvulos. ${ }^{61}$ Las nuevas plazas de maestros para la Escuela dejaron de solicitarse al director del Ave María y se sacaron a concurso público, anunciándose en periódicos de Madrid. ${ }^{62}$ De esta manera, el Consejo nombró dos nuevas maestras para párvulos y un maestro para niños. ${ }^{63}$ Por otro lado, se crearon los Consejos Escolares ${ }^{64}$ y se reformó la enseñanza de magisterio. En el programa educativo republicano influyeron factores ideológicos como el liberalismo, el socialismo y el laicismo, reflejo del programa llevado a cabo en Francia en los años finales del siglo XIX tras la implantación de la III República. ${ }^{65}$ En Almadén, el Consejo creó un Patronato Escolar a finales de 1931, cuyas principales misiones eran cooperar en la mejora de la Escuela, impulsar los deportes y las excursiones escolares, promover la relación de los niños con los de las otras escuelas de Almadén, organizar conferencias y proyecciones instructivas, y estrechar las relaciones entre la escuela y las familias de los alumnos. ${ }^{66}$ El Patronato Escolar fue poco a poco relegado de sus funciones y en 1935 solo tenía ya competencias administrativas.

\footnotetext{
tras año en el Tesoro Público a cuenta de los beneficios. Julio Zarraluqui Martínez, Los almadenes de azogue. La historia frente a la tradición (Madrid: Librería Internacional de Romo, 1934), 798.

61 AHMA, ACA, 25 de marzo de 1931, 3.

62 AHMA, ACA, 22 de enero de 1932, 8.

${ }^{63}$ AHMA, ACA, 15 de febrero de 1932, 15.

64 «Los Consejos Escolares procurarán ser los auxiliares eficaces de los consejos locales de enseñanza primaria dentro de las funciones que se les atribuyen...» (artículo 15 del Decreto de 9 de junio de 1931).

${ }^{65}$ Viñao, Escuela para todos..., 37.

66 AHMA, ACA, 18 de diciembre de 1931, 1-2.
} 


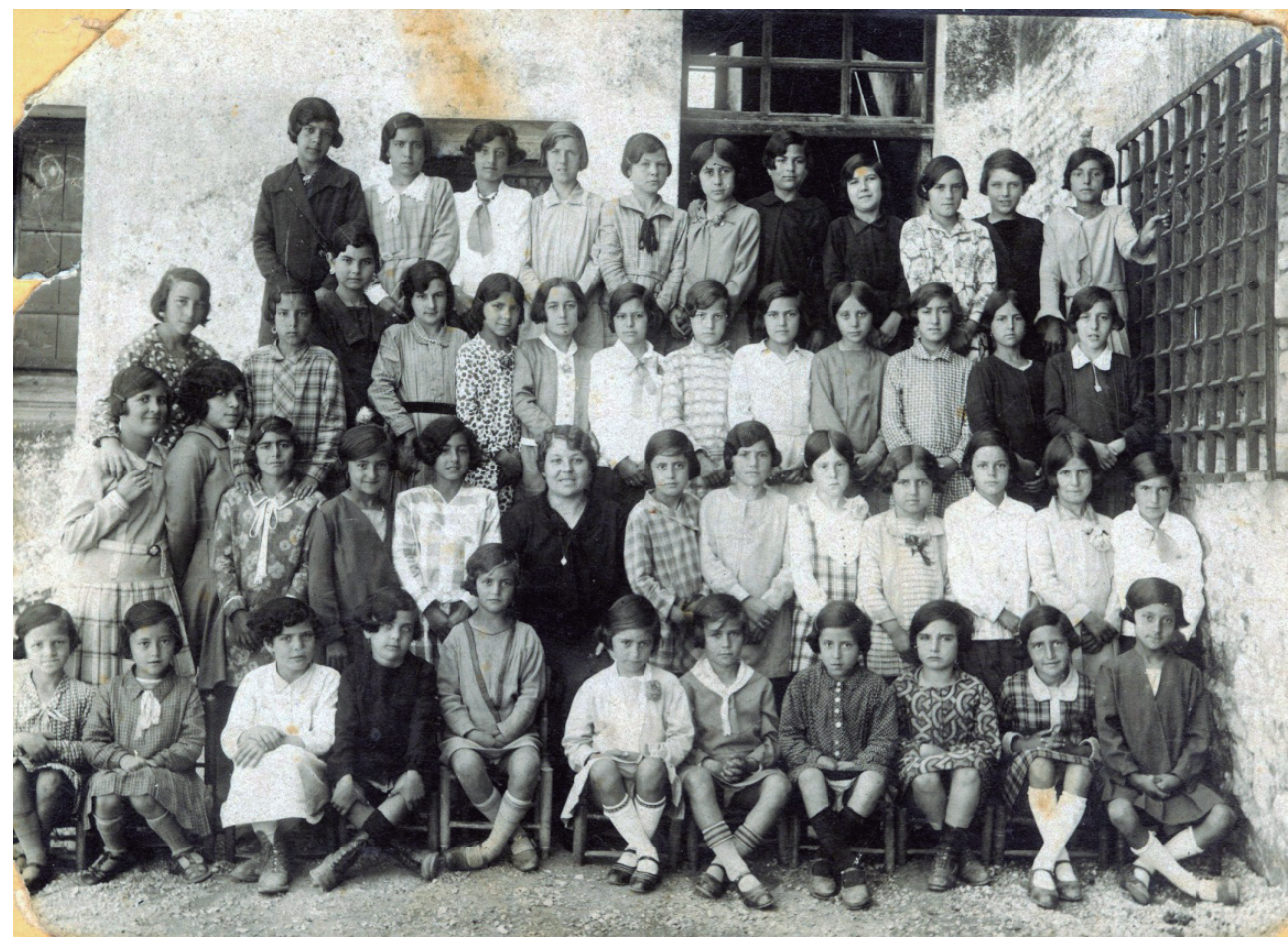

Imagen 2. Una maestra con sus alumnas hacia 1932. Fuente: mipuebloalmaden.blogspot.com

A principios de 1933, un grupo de unos 500 operarios de la mina constituyó la Asociación Mutua de Instrucción Primaria y Profesional, aportando para ella el 1\% de su salario. Esta asociación propuso una enseñanza más práctica, de modo que los alumnos aprendieran también algún oficio, a la par que adquirían los conocimientos teóricos. El Consejo apoyó esta propuesta y pronto los primeros talleres empezaron a funcionar: carpintería, electricidad, ajuste, etc., para los niños, y corte y confección para las niñas. Cuando el director general de Primera Enseñanza visitó Almadén en 1933, se comprometió a que el Ministerio de Instrucción Pública cooperaría en el sostenimiento de la Escuela. ${ }^{67}$ Entonces, César de Madariaga, director del establecimiento minero de 1931 a 1935, propuso al Consejo que dejara de sostener y administrar la Escuela y que fuera la Asociación Mutua de Instrucción Primaria la que

67 AHMA, ACA, 8 de febrero de 1933, 43. 
se encargara de su dirección y gestión con la ayuda del Consejo y del Ministerio de Instrucción Pública. El Consejo, que siempre había luchado por mantener el gobierno y la administración de la Escuela, dotándola de nuevos grupos escolares y más maestros a medida que pasaban los años, rechazó la propuesta del director de la mina. ${ }^{68}$

Por otro lado, los maestros avemarianos de la Escuela protestaron por la campaña que se había emprendido contra ellos, secundada por el diario local «Justicia», para mermar su prestigio. El Consejo se puso de parte de aquellos, afirmando que no tenía ningún motivo de queja de su comportamiento y respondiendo de la labor profesional que venían realizando. Almadén vivió en aquella época una situación permanente de conflicto, originado por los obreros sin trabajo. El problema era que la población iba creciendo y que no todos los jóvenes en edad de trabajar tenían asegurado un puesto en el establecimiento minero, la principal y casi única empresa de la comarca. Además, la progresiva, aunque lenta, mejora de los medios técnicos había hecho que la plantilla de la mina fuera disminuyendo desde mediados del siglo XIX. No obstante, en abril de 1934, el Consejo seguía manteniendo su postura respecto a de la Escuela: «Las Escuelas de las Minas de Almadén constituirán una dependencia aneja del Establecimiento Minero, con objeto de dar enseñanza primaria y elemental a los hijos de los obreros y empleados de las citadas minas que voluntariamente lo soliciten». ${ }^{69}$

La huelga revolucionaria de octubre de 1934 tuvo poca incidencia en Almadén, aunque seis obreros fueron detenidos de manera preventiva. Otra huelga en 1935 tuvo más seguimiento y además algunos piquetes impidieron la entrada de los operarios que querían trabajar al establecimiento minero. Pasquines de la Federación Anarquista Ibérica, la temible FAI, aparecieron en el pueblo y en la mina, instando a una huelga general indefinida y a la insurrección armada. El Consejo se vio finalmente desbordado por los acontecimientos y aceptó que la Escuela de Hijos de Obreros se transformara en una escuela nacional con nueve secciones, sometidas todas ellas a la inspección técnica del Estado. El Consejo se limitó desde entonces a abonar el salario de los maestros y

\footnotetext{
${ }^{68}$ AHMA, ACA, 5 de abril de 1933, 4-13.

${ }_{69}$ AHMA, ACA, 25 de abril de 1934, 5-12.
} 
los gastos de materiales y mantenimiento, así como a establecer las gratificaciones que estimaba oportunas. ${ }^{70}$

Los resultados electorales de las elecciones generales a Cortes de 16 de febrero de 1936 dieron el triunfo al Frente Popular, que trató de impulsar de nuevo la construcción de escuelas y la enseñanza media y universitaria, prestando especial atención a la juventud obrera. Eran tiempos convulsos y la inestabilidad política y la crisis económica frenaron la reforma educativa que la República había implantado con tanto empuje en el primer bienio. ${ }^{71}$ En Almadén, el Frente Popular se hizo con el control del establecimiento minero, exigiendo entre otros asuntos la destitución del director y maestros avemarianos de la Escuela. El 21 de febrero, don Escolástico dirigió una carta al Consejo en la que ponía en su conocimiento:

[...] que el 20 del actual, sobre las once y cuarto de la mañana, una gran muchedumbre invadió las escaleras y pasillos de la Escuela, llegando hasta la clase del que suscribe. Apostados en la puerta de ella y contenidos por el obrero de talleres, Brígido Herreros, lanzaron toda clase de insultos contra mi persona y mi honorabilidad. Momentos después irrumpían en el salón, ante el pavor de los pequeñuelos, lanzando gritos y vivas a la revolución, a la vez que proferían sin cesar toda clase de insultos [...].72

En la sesión del Consejo de Administración, celebrada el 6 de junio de dicho año, se debatió la destitución del director y de los maestros avemarianos de la Escuela llevada a cabo por el Frente Popular. ${ }^{73} \mathrm{El}$ Consejo ratificó su destitución, haciendo constar en el acta que el despido no afectaba en nada a su moralidad, honradez y competencia profesional. Además, aprobó que fueran indemnizados de acuerdo con lo estipulado en los contratos y que dos de ellos fueran nombrados empleados particulares del establecimiento minero como escribientes de última categoría. Los maestros manjonianos de la Escuela de Hijos de Obreros padecieron una nueva depuración al finalizar la guerra civil, aunque en

\footnotetext{
70 AHMA, ACA, 1 de marzo de 1935, 10-12.

71 Asensio, La enseñanza primaria..., 35.

72 AHMA, ACA, 24 de febrero de 1936, 1-3.

${ }^{73}$ AHN, FC-MA, legajo 2764, caja 1, 6 de junio de 1936.
} 
este proceso todos resultaron absueltos. El de Almadén no fue un caso único, ya que la mayoría de los maestros de Ciudad Real y otras provincias sufrieron una doble depuración, «... primero la frente-populista en plena guerra civil y tras finalizar esta, la depuración franquista... si bien el desconcierto de la guerra y la falta de una organización más precisa provocaron que las repercusiones de la depuración frente-populista fueran menores que las que luego iba a suponer la depuración franquista». ${ }^{74} \mathrm{El}$ director del establecimiento minero, los ingenieros del mismo y varios mandos intermedios, además del jefe de los Servicios Médicos, fueron también destituidos y desterrados de Almadén por el Frente Popular y el Consejo se limitó a acatar los ceses propuestos. ${ }^{75}$

Durante la guerra civil, la educación se convirtió en caldo de cultivo de la propaganda del régimen republicano, pero la enseñanza sufrió el lógico impacto de la dinámica bélica y de la política practicada en este periodo. ${ }^{76}$ La política de creación de escuelas durante la guerra se aceleró pero resulta difícil saber, cuantas se establecieron de manera provisional y cuantas de modo definitivo. ${ }^{77}$ Almadén permaneció en zona republicana durante toda la contienda. La línea del frente quedó establecida a unos 65 kilómetros al sur de Almadén, de modo que todo el norte de la provincia de Córdoba permaneció en manos de la República. En los tres años que duró la guerra, Almadén fue considerado un símbolo de la resistencia republicana, pues abasteció a la misma de divisas extranjeras con la venta de mercurio. Su cotización internacional ascendió en esos años, ya que las grandes potencias mundiales se aprovisionaron de él ante la inminencia de un gran conflicto internacional. Por ello, las tropas de Franco intentaron conquistar Almadén en dos ocasiones a lo largo de la guerra, años 1937 y 1938, pero no lo consiguieron. El mercurio de Almadén ocupó un lugar preferente en la Exposición Internacional de París de 1937, «... pues precisa que se ensalce con todo el interés que merece y se le cuide con todo el empeño que nuestro

\footnotetext{
${ }^{74}$ Sara Ramos Zamora, La depuración del magisterio de primera enseñanza en Castilla-La Mancha (1936-1945) (Madrid: Universidad Complutense, 2004), 1239.

75 AHMA, ACA, 24 de febrero de 1936, 3-12.

76 Asensio, La enseñanza primaria..., 38.

77 Asensio, La enseñanza primaria..., 38.
} 
comercio mundial requiere y necesita». ${ }^{78}$ Minas de Almadén fue declarada industria de guerra y a pesar de las enormes dificultades de suministros y transportes, consiguió mantener la producción de mercurio durante los tres años que duró la contienda.

La Escuela de Hijos de Obreros trató en ese periodo de continuar la enseñanza de los niños de Almadén e incluso procedió a organizar la de adultos. Maestros nacionales sustituyeron a los del Ave María expulsados y la maestra Amanda Jerez Martínez fue nombrada directora. ${ }^{79}$ En junio de 1937, con ocasión de la visita del inspector de Primera Enseñanza, se decidió la supresión de las vacaciones estivales, «debiendo marchar las escuelas al compás de intensificación del trabajo que se impone en estos momentos ante las necesidades de la guerra». ${ }^{80}$ En cuanto a las clases de adultos, se propuso que asistieran todas las personas mayores de catorce años de ambos sexos, que las clases fueran todos los días laborables de las diecisiete a las diecinueve horas y que los maestros que las impartieran concediesen voluntariamente la gratificación que les correspondiera a favor de los huérfanos de los mineros asturianos y otras víctimas de la revolución de octubre de $1934 .{ }^{81}$

Las dificultades aumentaron con el transcurso de 1937 y Almadén se convirtió en un refugio para los heridos y enfermos del frente, así como para sus familiares. En la Escuela de Hijos de Obreros se alojó temporalmente el batallón Jaén y se propuso la instalación de un hospital de sangre con capacidad para trescientas camas, lo que al final no se llevó a cabo. ${ }^{82} \mathrm{~A}$ lo largo de dicho año, la situación continuó empeorando ${ }^{83} \mathrm{y}$ el Consejo hubo de ayudar a los vecinos de Almadén e incluso al Ejército de la República destinado en el frente de Extremadura. A principios de enero de 1938 se tuvo que poner a disposición de los comedores de

\footnotetext{
${ }^{78}$ AHMA, Mercurio Español de Almadén, Folleto de Minas de Almadén para la Exposición Internacional de París, 1937.

79 AHMA, ACA, 22 de febrero de 1937, 2.

${ }^{80}$ AHN, FC-MA, legajo 3049, caja 3.

${ }^{81}$ AHN, FC-MA, legajo 3049, caja3.

82 AHMA, ACA, 16 de octubre de 1937, 11.

${ }_{83}$ Tal vez por ello, la directora Amanda Jerez solicitó un permiso sin sueldo y se incorporó al frente de guerra como miliciana de la cultura (AHN, FC-MA, legajo 3051, caja 3). En enero de 1938, el Consejo ordenó su cese definitivo (AHN, FC-MA, legajo 3049, caja 3).
} 
asistencia social los artículos del economato minero ${ }^{84}$ y en octubre de dicho año se hubo de ayudar económicamente al Ayuntamiento ante el aumento considerable de los forasteros que llegaban a Almadén en busca de refugio. ${ }^{85}$ En diciembre de 1938 fue el propio director del establecimiento minero, quien sin autorización del Consejo, expidió un libramiento de mil pesetas para contribuir a la campaña de invierno del Ejército de Extremadura. ${ }^{86}$

Aunque el alumnado infantil de la Escuela aumentó en los primeros meses de la guerra, comenzó a disminuir con el paso del tiempo, seguramente debido a que los niños se vieron obligados a realizar otras tareas para ayudar a su familia en aquellos difíciles años. Así es cómo un alumno, Tomás Avilero, recuerda aquellos años de guerra:

[...] en cuanto al colegio no hubo interrupción alguna, lo que sí hubo fue escasez de algunos artículos de primera necesidad que no abundaban mucho en esta zona; a mediados de la guerra tuvieron que racionarlos debido a que aumentó mucho el número de habitantes de Almadén, a consecuencia de las tropas destacadas y de los evacuados procedentes de Extremadura y Andalucía. ${ }^{87}$

Tabla 1. Evolución del alumnado durante la guerra civil

\begin{tabular}{|l|c|c|}
\hline Fecha & Alumnos & Asistencia \\
\hline Septiembre 1936 & 601 & $90 \%$ \\
\hline Marzo 1937 & 672 & $81 \%$ \\
\hline Julio 1937 & 529 & $60 \%$ \\
\hline Enero 1938 & 427 & $54 \%$ \\
\hline Julio 1938 & 422 & $33 \%$ \\
\hline
\end{tabular}

Elaboración propia. Fuente: AHMA, ACA.

\footnotetext{
${ }^{84}$ AHMA, ACA, 10 de enero de 1938, 3.

85 AHMA, ACA, 7 de octubre de 1938, 3.

86 AHMA, ACA, 10 de diciembre de 1938, 1.

87 Gallego-Preciados, Colegio Hijos de Obreros de Almadén..., 101.
} 


\section{LA ESCUELA DE 1939 A 1959}

Cuando a finales de marzo de 1939 las tropas de Franco tomaron Almadén, los mandos militares se dirigieron urgentemente al almacén de mercurio porque temían que el ejército republicano hubiera destruido a propósito las reservas de dicho metal, pero no sucedió así y Almadén pudo continuar su venta internacional a través del Cártel Mercurio Europeo, cuyo acuerdo se había roto durante la guerra civil española. En 1939, la España de Franco y la Italia de Mussolini impulsaron la venta de mercurio, sobre todo a Alemania y Japón, pues se avecinaba la Segunda Guerra Mundial y el mercurio era un metal estratégico, así que su cotización internacional creció rápidamente. ${ }^{88}$

En mayo de 1939 ya se había nombrado un nuevo Consejo de Administración de Minas de Almadén y Arrayanes, a cuyo frente estaba Jesús Marañón, abogado del Estado. En vista de la favorable situación del mercurio en el mercado internacional, se utilizaron todos los medios posibles para incrementar la producción. Como muchos mineros habían sido represaliados, el Consejo no dudó en solicitar reclusos mineros al Patronato Central para la Redención de Penas por el Trabajo, organismo del Ministerio de Justicia encargado de distribuir a los presos políticos, que no a los comunes, por obras públicas, minas, industrias y talleres según sus conocimientos y habilidades ${ }^{89}$. A pesar de todas las dificultades de materiales y suministros en el establecimiento minero, el mercurio fue un negocio muy rentable en los primeros años de la posguerra, de modo que los ingresos de Minas de Almadén al Tesoro Público crecieron año tras año. ${ }^{90}$

Tras la guerra civil, el mundo educativo también sufrió un profundo cambio y los presupuestos anuales fueron tan escasos que un tercio de los niños permaneció sin escolarizar. La educación primaria quedó en manos de la Iglesia católica y los niños y niñas, separados por sexo, no

\footnotetext{
${ }^{88}$ El precio del frasco, unidad de comercialización del mercurio y realizado en hierro, con una capacidad de 2,5 litros y 34,5 kilogramos, había ascendido de 95 dólares USA a comienzos de 1938 hasta 165 en septiembre del mismo año.

89 Ángel Hernández Sobrino y Javier Vinagre Moreno, Los reclusos mineros de Almadén, 1940-1944 (Ciudad Real: Fundación Almadén-Francisco Javier de Villegas, 2012), 8-20.

${ }_{90}$ Además, el mercurio se vendía en dólares, lo que suponía un ingreso de divisas para la depauperada Hacienda Pública española.
} 
solo aprendieron la rígida moral católica sino también la formación del espíritu nacional. En primer lugar, se les enseñaría el conocimiento de Dios y la religión, pero también se darían lecciones diarias del Movimiento, su génesis e historia, exaltándose las figuras de los llamados mártires de la Cruzada, como los que combatieron en el Alcázar de Toledo, Oviedo o Teruel. ${ }^{91}$ Además, se prohibió enseñar en otra lengua que no fuera el castellano y crucifijos y retratos de Franco y José Antonio adornaban todas las aulas:

El oprobio de una escuela laica ha terminado, para formar españoles hondos creyentes y patriotas austeros [...]. La Escuela tiene que recoger el ambiente heroico de las juventudes guiadas por el Caudillo a la victoria y la cooperación de figuras insignes como la de José Antonio, genial alentador de la juventud española en horas de desconcierto. ${ }^{92}$

Europa dejó de ser un modelo pedagógico y se rechazó de manera categórica cualquier idea que viniera del exterior. En la Ley de Reforma de la Enseñanza Media de 20 de septiembre de 1938 se alentaba textualmente a «... la revalorización de lo español y, en definitiva, a la extirpación del pesimismo anti-hispánico y extranjerizante, hijo de la odiosa y mendaz leyenda negra». Se trataba en resumen de eliminar cuanto antes las reformas educativas de la República y regresar a la escuela católica tradicional. Así lo afirmaba Romualdo de Toledo, director general de Enseñanza Primaria, en Burgos, año 1939: «Vuelve la tradición, quiere decirse que vuelve la escuela española de nuestros siglos mejores, asentada en la Parroquia y la familia, y adornada con las virtudes nacionales de disciplina, jerarquía, misión y hermandad...». ${ }^{93}$

La represión llevada a cabo contra los maestros republicanos fue muy dura, pues las autoridades franquistas consideraron a estos docentes como elementos sumamente peligrosos, ya que les acusaba de haber

\footnotetext{
${ }^{91}$ La manipulación ideológica fue tan burda que se llegó a comparar a Franco con Viriato, pues si este había sido capaz de derrotar a la todopoderosa Roma, Franco había vencido al comunismo.

92 J. Iniesta, «Circular dirigida a los maestros de la provincia de Barcelona por el inspector en jefe de la enseñanza primaria», 6 de junio de 1939, en Historia de España, vol. IX. La dictadura de Franco, ed. Borja de Riquer Permanyer (Barcelona: Crítica/Marcial Pons, 2013), 851-852.

${ }_{93}$ Alfonso Iniesta Corredor, Garra marxista en la infancia (Burgos: Hijos de Santiago Rodríguez, 1939), 11.
} 
inoculado en niños y niñas los ideales de la República. Se estima que 50.000 maestros nacionales fueron destituidos en toda España, a pesar de que la mayoría de ellos no estaba afiliada a partidos republicanos ni tampoco era afín a partidos de izquierda. ${ }^{94}$ En ciertos casos todavía fue peor, pues las sentencias de los tribunales militares condenaron a algunos a pena de muerte o largas penas de prisión. Condenas de doce años fueron frecuentes, como es el caso de un maestro de Ciudad Real, quien «... antes del Glorioso Movimiento Nacional pertenecía al Partido Radical y después se hizo comunista». ${ }^{95}$ Sentenciado a doce años por rebelión, durante su condena en la prisión de Ciudad Real fue lector de patio y auxiliar de biblioteca. ${ }^{96} \mathrm{~A}$ finales de 1940 había disponibles para el desempeño de puestos similares al citado 1.357 maestros en el fichero fisio-técnico del Patronato Central para la Redención de Penas por el Trabajo. ${ }^{97}$

Por otra parte, el nuevo aparato escolar instauró de nuevo y sin pérdida de tiempo la religión en todas las escuelas, a la que se añadió el amor a la patria, de modo que religión y educación patriótica se complementaban. Comenzó entonces además un proceso de depuración de las bases sociales republicanas y de su política educativa, a la vez que se legitimaba el golpe de estado y la dictadura de Franco. Los docentes, como transmisores de aquella memoria escolar de la República, fueron reducidos al silencio y al olvido. ${ }^{98}$ Se calcula que una cuarta parte de los docentes de primera enseñanza fueron sancionados en el conjunto de España y en Castilla-La Mancha sucedió algo similar, «... pudiendo confirmar que el sector más castigado en todas las partes investigadas fue el de maestros, siendo también el colectivo en el que recayeron las sanciones más duras $\gg .99$

\footnotetext{
${ }_{94}$ Ramón Navarro Saladrinas, «El franquismo, la escuela y el maestro (1936-1975)», Historia de la Educación 8 (1989): 167-180. http://campus.usal.es/ revistas_trabajo/index.php/0212-0267/article/ viewFile/6832/6818

95 Archivo Histórico Provincial de Ciudad Real (AHPCR), expedientes de reclusos (1939-1952), caja $118, \mathrm{n}^{\circ} 405966$.

96 Idem.

${ }_{97}$ Patronato Central para la Redención de las Penas del Trabajo, El primer año de la Obra de Redención de Penas. Memoria 1939-1940, Madrid, 1 de enero de 1941, 40.

98 Juan Manuel Fernández Soria, «Desmemoria de la educación republicana en el franquismo», en Entre el olvido y la memoria. Educación, mitos y realidades, ed. Teresa González Pérez (Valencia: Tirant Humanidades, 2018), 101.
}

99 Ramos, La depuración del magisterio de primera enseñanza..., 1245-1246. 
También en Almadén se dieron prisa en desmemoriar la educación republicana y se procedió a la depuración de quince maestros, seis de los cuales eran de la Escuela de Hijos de Obreros. A principios de abril de 1939, don Escolástico ya había sido repuesto en su cargo de director por el Consejo de Administración y readmitidos el resto de maestros manjonianos. ${ }^{100}$ Como no había suficientes docentes, el Consejo contrató a dos maestros y una maestra nacionales, quienes habían mostrado adhesión o simpatía por el llamado Movimiento Nacional. ${ }^{101}$ Mientras, el director de la Escuela dio cuenta al Consejo de cómo pensaba recuperar el espíritu nacional y reorganizar la enseñanza «... para combatir el estrago producido por los rojos». ${ }^{102}$

En principio se pensó en ampliar el número de clases hasta diez para un cupo de 600 alumnos, si bien en septiembre de 1939 había 704 alumnos matriculados, así que hubo de buscarse un local adecuado en Almadén para dar clases a un centenar. ${ }^{103}$ En el día de reinauguración de las escuelas «... se celebró el acto solemne de izarse la Bandera Nacional en el edificio de las minas y colocarse el Crucifijo en los locales y clases de los alumnos». ${ }^{104}$ En tan brillante acto solo hubo una objeción y es que «...no se apreció la presencia de obreros del Establecimiento, retraimiento doloroso ya que se trataba de inaugurar también la obra cultural que realiza el Consejo en beneficio de sus hijos». 105

El cura párroco de Almadén elevó sus quejas al Consejo de Administración, pero no debió quedar satisfecho con su actitud, por lo que

\footnotetext{
100 Hay que tener en cuenta que los maestros no fueron los únicos represaliados en Almadén al término de la guerra civil. Si durante la etapa del Frente Popular, el director, los ingenieros y otros mandos de la mina fueron expulsados del establecimiento minero, al comienzo de la posguerra 1.339 obreros fueron expedientados y sancionados bajo la acusación de haber cometido faltas más o menos graves. Hernández Sobrino, Los mineros del azogue, 447.

101 Se calcula que en 1940 había en la provincia de Ciudad Real 500 maestros (uno por cada 200 niños) y que se necesitaban 500 más.

102 AHMA, ACA, 7 de junio de 1939, 10-13. Era tal el ímpetu de D. Escolástico que pronunció una serie de conferencias patrióticas, que el mismo Consejo reconoció que habían resultado un éxito de público.

103 Según el INE, Almadén tenía 12.988 habitantes en 1940.

104 AHMA, ACA, 14 de junio de 1939, 11-13.

105 AHMA, ACA, 14 de junio de 1939, 11-13.
} 
se dirigió después al Ministerio de Justicia para denunciar que «... hay muchas viudas pensionistas que hacen vida marital con obreros de las minas y muchos niños sin bautizar». ${ }^{106}$ Poco después, el vicario general de la sede vacante del Priorato de las Órdenes Militares escribió al subsecretario del Ministerio de Gobernación para informarle de la apatía e indiferencia religiosa de la masa obrera de Almadén, y es que mientras que a los niños se les proporcionaba en la Escuela una enseñanza religiosa y patriótica, recibiendo a diario lecciones de Religión y del Movimiento Nacional, sus padres mostraban escaso fervor.

El Consejo de Administración se involucró en que «... aquella desvariada población obrera volviera al seno de la Iglesia...» y organizó de acuerdo con la Parroquia una misión en 1943. ${ }^{107}$ En ella intervinieron los padres jesuitas Marina y Valle, consiguiendo que más de 2.000 personas concurrieran a la misma. Ante tal éxito, un año después se celebró una nueva misión dirigida por cuatro sacerdotes del Sagrado Corazón de María. Otra vez hubo una gran asistencia y como acto final el obispo prior de las Órdenes Militares celebró una misa de campaña en el recinto del establecimiento minero. A las misiones cuaresmales se unieron otras manifestaciones de religiosidad popular, como cofradías, hermandades, procesiones, peregrinaciones y romerías, grupos de adoración eucarística y de culto mariano, toda una ofensiva social católica contra el laicismo auspiciado por la República.

Como había muchos niños todavía sin escolarizar, ya en 1939 el Ministerio de Educación Nacional decidió aumentar el número de maestros de la Escuela hasta doce, contratando seis de ellos a su cargo a principios de 1940.108 Ante las estrecheces económicas de las familias almadenenses, el Consejo decidió poner en marcha de nuevo, pues ya habían funcionado durante la República, el ropero y la cantina escolares, y también recuperar la concesión de becas. ${ }^{109}$ El ropero escolar tenía

\footnotetext{
106 AHMA, ACA, 20 de septiembre de 1939, 22-23.

107 AHMA, ACA, 22 de marzo de 1943, 10-11.

108 AHMA, ACA, 21 de febrero de 1940, 29.

109 Los mineros de Almadén siempre han tenido un salario menor que los de otras minas metálicas o de carbón, pues el vapor de mercurio existente en las labores subterráneas les provocaba
} 
como misión «...proveer a los niños de las más indispensables prendas de abrigo, ya que hay muchos que por estar sus padres sancionados, otros encarcelados, y no pocos por ser hijos de viuda o huérfanos carecen de calzado y de ropas». ${ }^{110}$ Mientras, la cantina escolar daba una comida caliente diaria a los niños pobres, «... ya que con ello se favorece grandemente a una gran parte de la población escolar, cuyas familias se encuentran harto necesitadas». ${ }^{111}$

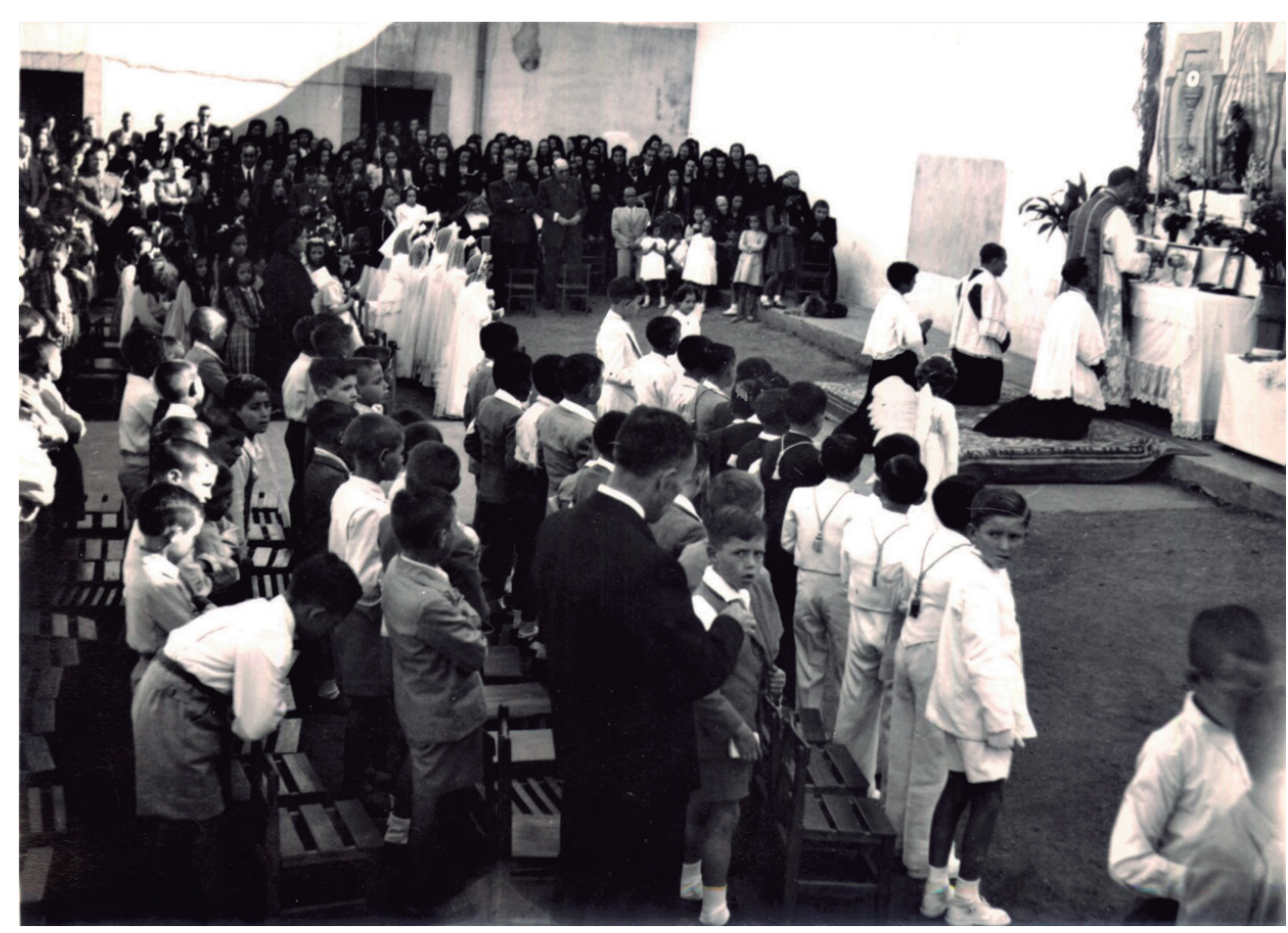

Imagen 3. Primeras comuniones hacia 1943. AHN, FC-MA, Fondo fotográfico, n. ${ }^{\circ} 88$.

En julio de 1940 se empezó a confeccionar un nuevo reglamento para la Escuela, por el que volvía a ser un centro de enseñanza conforme con

hidrargirismo (azogamiento), lo que no les permitía trabajar a diario. Desde 1865 en que fue aprobada una nueva reglamentación laboral, los mineros solo daban ocho jornales al mes de seis horas cada uno. Como casi todos los mineros tenían obligaciones familiares, se veían en la necesidad de tener otra actividad que complementara sus ingresos económicos.

110 AHMA, ACA, 28 de septiembre de 1939, 17.

111 AHMA, ACA, 28 de septiembre de 1939, 17. 
el sistema pedagógico manjoniano. La Escuela seguía dependiendo del Consejo de Administración de las minas y, por tanto, era una institución docente particular, si bien se hallaba sometida también a la Dirección General de Primera Enseñanza en relación con el nombramiento y cese del personal docente, así como a la jurisdicción gubernativa y disciplinaria de los funcionarios del ministerio de Educación Nacional. Por tanto, la nómina de los seis maestros y seis maestras era abonada por dicho Ministerio, si bien el Consejo de Administración les otorgaba diversas gratificaciones, con lo que casi duplicaban su salario. ${ }^{112} \mathrm{Y}$ es que el Consejo no solo trataba de que los hijos de los mineros tuvieran educación primaria, sino que tal y como afirmaba su presidente dos meses después del término de la guerra civil, «... que el generoso Estado español llegue a contar en Almadén con servidores absolutamente adictos...». ${ }^{113}$

Para el buen régimen de la Escuela se constituyó el Patronato Social, integrado por el director técnico de la mina, quien actuaba como presidente, el interventor contador del establecimiento minero, el médico jefe de los Servicios Sanitarios de dicho establecimiento, el director de la Escuela, el capellán de los mineros y uno de los maestros, quien actuaría como secretario. Su misión más importante era promover ante el Consejo las medidas adecuadas para la mejor educación e instrucción de los alumnos y resolver los problemas e incidencias del día a día de la Escuela. En ella se cursaban todas las asignaturas establecidas en las escuelas de primera enseñanza, pero siguiendo las directrices que se practicaban en las escuelas manjonianas: la intuición, la experimentación, los gráficos didácticos, los trabajos manuales y la conversación, obligando al alumno a que participara de un modo activo en la enseñanza. ${ }^{114}$

La Escuela de Hijos de Obreros de Almadén retomaba así el ideario educativo del padre Andrés Manjón después del período republicano y de la guerra civil. De acuerdo con el pensamiento del activismo pedagógico, en Almadén llevaban a los alumnos a visitar los centros de trabajo

\footnotetext{
112 El salario de un maestro era de 3.000 pesetas anuales, pero el Consejo les otorgaba otras 2.500 pesetas más al año, de las cuales 750 eran para vivienda y 1.750 por las clases complementarias que daban (enseñanzas del hogar y corte y confección para las niñas y oficios manuales para los niños).

113 AHMA, ACA, 28 de mayo de 1939, 12.

${ }_{114}$ AHMA, ACA, 9 de agosto de 1940.
} 
del establecimiento minero, así como también a excursiones campestres «... que fomenten el espíritu de camaradería y el amor a la Naturaleza». ${ }^{115}$ Por otra parte, «... será obligatoria la enseñanza de cánticos religiosos y patrióticos, y de canciones regionales. Con todo cuidado y atención se atenderá a la formación religiosa y a la práctica de los deberes y devociones de nuestra Santa Religión Católica».116

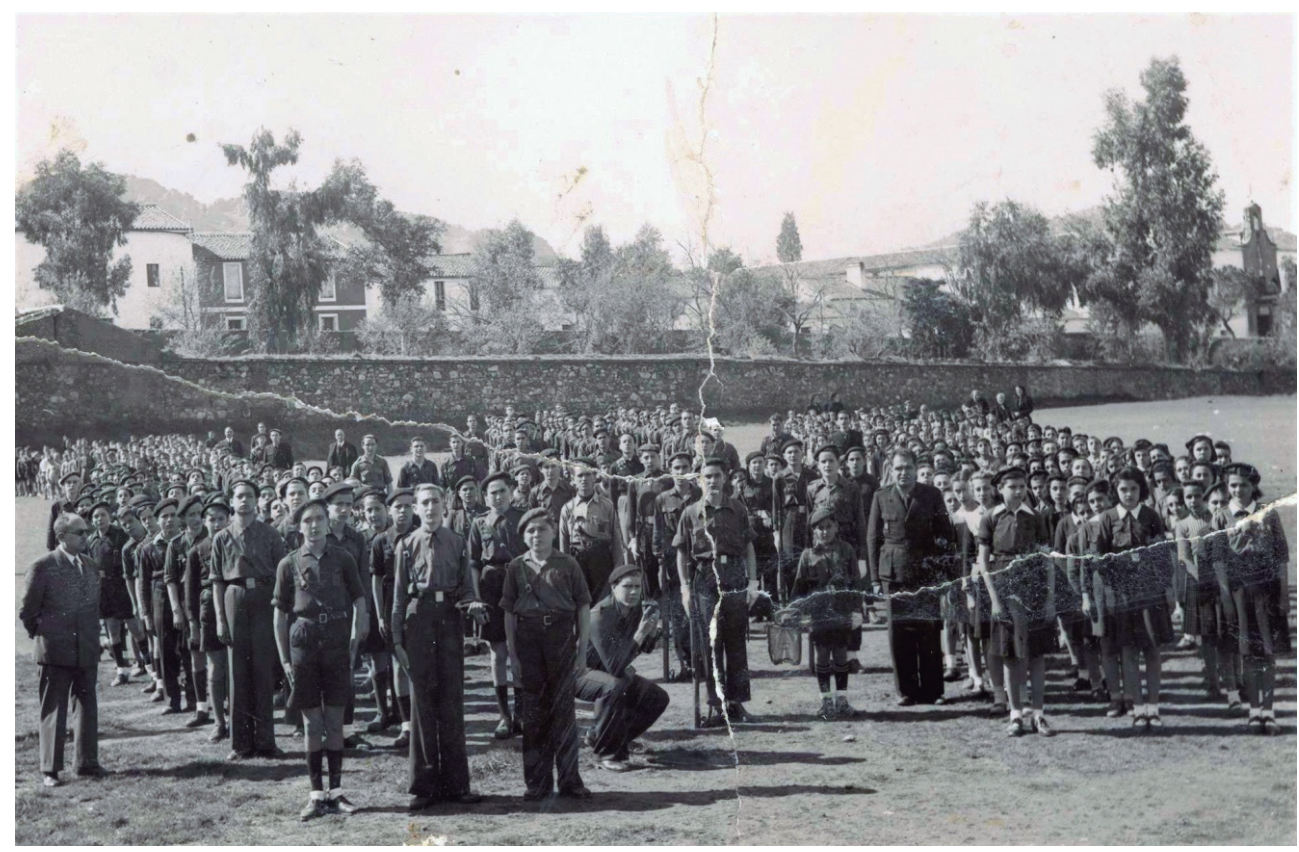

Imagen 4. Centuria de flechas de la Falange, año 1941. Fuente: mipuebloalmaden.blogspot.com

Así pues, a las prácticas religiosas diarias, como el rezo del Ave María y del Rosario, se unió toda la parafernalia nacional-católica. ${ }^{117}$ Todas las mañanas en el patio de la escuela y antes de entrar en clase niños y niñas formaban en filas, se izaba la bandera nacional y se cantaba el Cara al Sol con brazo y mano derechos extendidos. No obstante estas prácticas marciales, la Falange fue quedando poco a poco marginada del proyecto

\footnotetext{
115 AHMA, ACA, 9 de agosto de 1940.

116 AHMA, ACA, 9 de agosto de 1940.

117 En diciembre de 1940 se creó el Frente de Juventudes, al que debían pertenecer obligatoriamente los estudiantes que tuvieran entre ocho y dieciocho años.
} 
educativo del régimen franquista, tal y como denunciaba Miguel Primo de Rivera en su carta de dimisión como gobernador civil de Madrid: «El Frente de Juventudes...hace de nuestra esperanzada juventud...un numeroso y perplejo conjunto de muchachos que, de seguir así, llegará el día en que duden si nuestra Cruzada fue algo más que una matanza entre españoles...». ${ }^{118}$

El 30 de marzo de 1940, Teodoro Babiano, uno de los alumnos de la Escuela, reflejaba en su cuaderno de deberes el binomio de religión y espíritu nacional que le imbuía a diario su maestro:

Han terminado las vacaciones de Semana Santa y fiesta del Aniversario de nuestra liberación. La Semana Santa ha sido, quizá, una de las mejores de nuestro pueblo, dado el fervor religioso y la asistencia tan enorme a las procesiones, siendo la última, el Santo Entierro, una verdadera manifestación de fe religiosa. Las fiestas del Aniversario de la Liberación dieron comienzo el día 27 por la tarde con un simulacro de la toma del pueblo por las fuerzas de guarnición, continuando con una gran manifestación popular hasta la parroquia donde entonaron un Tedeum en acción de gracias [...]. ${ }^{119}$

Luis Babiano, primo del anterior, tiene un buen recuerdo de aquella escuela y de sus maestros, a pesar de que:

[...] en invierno hacía mucho frío en el aula porque no había calefacción ni estufa de ningún tipo [...], en cada una éramos unos 50 niños y allí aprendí que España era Una, Grande y Libre, todos los días cantábamos el Cara al sol antes de entrar en clase y cuando desfilábamos por alguna festividad, aquel otro himno que decía Prietas las filas, recias, marciales, nuestras escuadras van [...], pero más que la política era la religión la que impregnaba todo, el saludo permanente del Ave María repetido hasta la saciedad y el Rosario diario [...]. ${ }^{220}$

\footnotetext{
118 Damián Alberto González Madrid, «Educación y dictadura franquista. Los años cuarenta», en $L a$ educación en Castilla-La Mancha en el siglo XX, dir. María del Mar del Pozo (Ciudad Real: Biblioteca Añil, 2007), 8. https://previa.uclm.es/AB/humanidades/seft/pdf/textos/damian/educacion.pdf.

119 Gallego-Preciados, Colegio Hijos de Obreros de Almadén..., 89.

${ }^{120}$ Comunicación personal de Luis Babiano, alumno de Hijos de Obreros desde 1942 hasta 1950.
} 
En octubre de 1940, el Consejo creó la llamada Escuela de Aprendizaje en la Industria, en la que, como clases complementarias, los niños de más de diez años recibían instrucción en alguna de estas especialidades: mecánica, carpintería, guarnicionería, imprenta, dibujo, encuadernación, marquetería... Estas prácticas se realizaban por la tarde, a veces en la propia escuela y otras en los pequeños talleres del pueblo. ${ }^{121}$ En marzo de 1942, la citada Escuela de Aprendizaje en la Industria pasó a llamarse Escuela de Artesanía, «... uno de los postulados del Nacional-Sindicalismo, plasmando las orientaciones marcadas por el Nuevo Estado en su Fuero del Trabajo».122 Los alumnos más aventajados tenían como premio el poder hacer prácticas posteriores en los talleres del establecimiento minero, «... con la doble finalidad de ir seleccionando y formando entre los alumnos de nuestra Escuela unos buenos artesanos y así tener en ellos plantel para escoger los operarios que precisen las distintas especialidades de nuestro Establecimiento minero».123 Se conseguía así el cumplimiento de uno de los principios de la pedagogía manjoniana, que procuraba que cuando los niños dejasen la escuela, tuvieran una ocupación en la sociedad y fueran «... obreros callados y laboriosos». ${ }^{124}$

Las niñas, convenientemente separadas de los niños en otras aulas, recibían una educación que en parte era diferente, con la finalidad de saber ejercer bien en el futuro su papel de esposas y madres. Su educación se dirigía a convertirlas en buenas amas de casa, instruyéndolas en conocimientos de economía doméstica, labores del hogar, cocina y costura. En sus talleres, las niñas aprendían corte y confección, tejían alfombras e hilaban manteles. Sus bellas labores adornaban la iglesia de San Juan, que era la capilla de los mineros desde hacía tres siglos, y el chalé del Consejo de Administración en Almadén. Los mejores trabajos eran expuestos al final de cada curso y el beneficio de la venta de los mismos se destinaba a la cantina escolar, la cual había pasado de tener cincuenta y cuatro comensales en el curso 1941-1942 a sesenta en el $1943-1944 .{ }^{125}$

\footnotetext{
121 AHMA, ACA, 23 de octubre de 1940, 43-46.

122 AHMA, ACA, 11 de marzo de 1942, 6-7.

${ }^{123}$ AHMA, ACA, 17 de marzo de 1942, 12-16.

124 AHMA, ACA, 4 de febrero de 1944.

125 AHMA, ACA, 14 de junio de 1944, 32-33.
} 


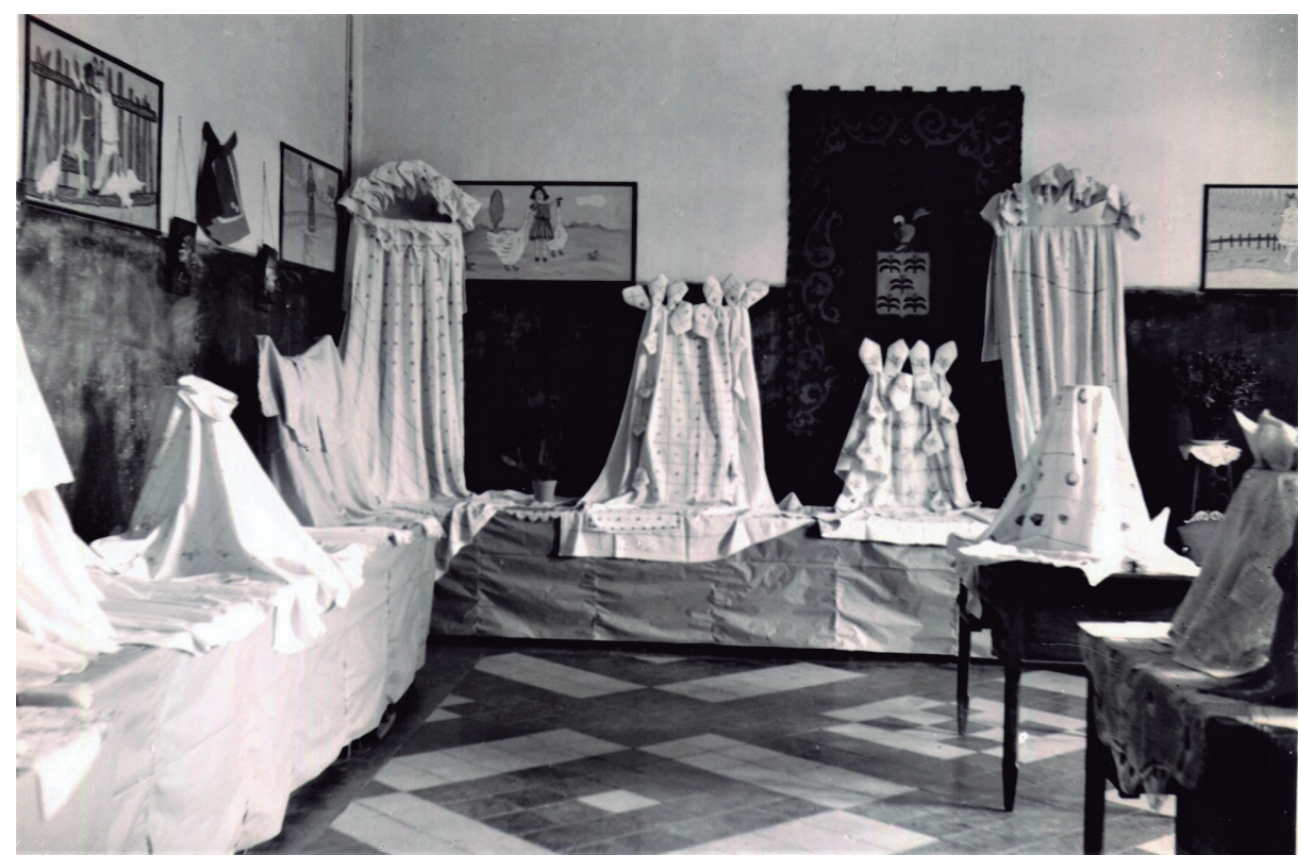

Imagen 5. Exposición de trabajos manuales Fuente: AHN, FC-MA, Fondo fotográfico, n. ${ }^{\circ} 100$

Como la Escuela de Hijos de Obreros no era suficiente para escolarizar a todos los niños de Almadén, se crearon otras adscritas a ella, cuyos alumnos aventajados tenían derecho a asistir a las clases de artesanía. A los más de 600 niños y niñas que asistían a la Escuela de Hijos de Obreros en noviembre de 1942, había que sumarles otros 266 que estudiaban en las Escuelas Nacionales. Además, en dicho año se creó una sección de párvulos, ${ }^{126}$ con lo que el presupuesto anual del Consejo para la Escuela alcanzó las 200.000 pesetas. Aun así, en diciembre de 1943 seguía habiendo 200 hijos de mineros sin escolarizar, pues la Escuela Hijos de Obreros no tenía capacidad suficiente, por lo que el Consejo intentó que asistieran a las Escuelas Nacionales a cambio de otorgar a estas una subvención. ${ }^{127}$

126 Orden Ministerial de 8 de octubre de 1942 (BOE del 20 de octubre). En dicho curso escolar había 16 maestros (3 provisionales) y 6 secciones de niños, 6 de niñas y la de párvulos.

127 AHMA, ACA, 10 de diciembre de 1943, 33-34. 
De nuevo y como venía sucediendo desde tiempo atrás, la infancia tuvo que ayudar en los años de posguerra a la economía familiar para no pasar hambre, así que algunos padres preferían que sus hijos trabajasen a que asistieran a la escuela. El Consejo era consciente de la situación y repartió en diciembre de 1943 ropas a los niños (zapatos, jersey y pantalón) y a las niñas (zapatos, ropa interior y falda o delantal), y «... aun así, algunos niños iban descalzos..., el modo de proporcionarles por lo menos un par de zapatillas...». ${ }^{128}$ En 1945, España solo invertía el 5\% en educación, mientras que en Inglaterra suponía el 20\%, y todavía en 1950, el 45,7\% de la infancia española permanecía sin escolarizar. ${ }^{129}$

La pedagogía manjoniana consideraba a La Naturaleza como un reflejo de Dios y fomentó la enseñanza al aire libre, donde se aprendía jugando y trabajando. Decía el padre Manjón que «... había que cultivar cuantos gérmenes de perfección física y espiritual ha puesto Dios en el hombre...»,130 así que la Escuela de Hijos de Obreros, fiel reflejo de los principios pedagógicos manjonianos, creó la colonia escolar en mayo de 1941 y la repitió en años sucesivos. En un principio, el director de la Escuela propuso al Consejo que la colonia escolar se realizara en una playa del Atlántico, pero el presupuesto era muy elevado y el proyecto fue desestimado. ${ }^{131}$ A cambio, se instaló en la huerta del Vivero, una zona con abundantes árboles y agua de la Dehesa de Castilseras. ${ }^{132}$ En 1941 asistieron a la colonia 70 niños, elegidos entre los más necesitados, cuya estancia costó al Consejo 6.000 pesetas. En 1942 ya se había organizado en la colonia infantil «... una buena huerta, cuyos productos se han consumido en la cantina escolar y en el hospital minero».133

\footnotetext{
128 AHMA, ACA, 10 de diciembre de 1943, 33.

129 Ramón Navarro Saladrinas, La enseñanza primaria durante el franquismo (1936-1975) (Barcelona: Promociones y Publicaciones Universitarias, 1990), 118 y 175.

130 Manjón, Discurso leído en la solemne apertura del Curso Académico..., 5.

131 AHMA, ACA, 23 de mayo de 1941, 7.

${ }^{132}$ La dehesa de Castilseras es una finca situada en el término municipal de Almadén en su mayor parte y de más 8.500 hectáreas de extensión. Consignada a la mina desde el medievo, cuando la propietaria del yacimiento de azogue era la Orden de Calatrava, en 1778 el papa Pío VI aceptó su incorporación a la Corona de España, la que a su vez la cedió a los mineros de Almadén para que se sanearan y recuperaran la salud perdida en los trabajos de la mina.
}

133 AHMA, ACA, 24 de marzo de 1942, 18-19. 
En mayo de 1943, un centenar de niños disfrutaron de la colonia escolar. De su estancia hizo el periodista almadenense Luis Cavanillas Ávila la siguiente reseña:

A primera hora es izada la bandera nacional a toque de clarín, en medio de la espesura de jara y tomillo de la sierra de Cordoneros. Acto seguido los niños, después de unos ejercicios gimnásticos, desayunan y se trasladan a la sombra de los pinos, robles y otros árboles del vivero para allí recibir bajo un régimen pedagógico especial las diferentes enseñanzas escolares. Después de la comida y siesta se reanudan nuevamente las clases. Terminadas estas y en alegre camaradería entre cánticos e himnos patrióticos, después del rezo del Santo Rosario, vuelven al campamento, arrían bandera y la paz del reposo les conforta para que con el nuevo día puedan emprender su cotidiana tarea. ${ }^{134}$

En 1944, Alemania y Japón tenían perdida la guerra y la cotización internacional del mercurio se desplomó, al igual que la del wolframio y otros metales. Los reclusos mineros, enviados a la mina de Almadén por el Patronato para la Redención de Penas por el Trabajo, marcharon a otros destinos, mientras el presidente del Consejo de Administración advertía:

Nos hemos de enfrentar a una época de grandes sacrificios, que nos ha de resultar aún más dura después de la gran prosperidad que hemos vivido en estos últimos cuatro años [...]. El Estado Español, siempre paternal y en Almadén paternalísimo, ha de procurar reducir al mínimo los sacrificios que tenga que sufrir nuestra población obrera [...].135

A pesar de la crisis, en mayo de 1944 también hubo colonia escolar en Castilseras. La gran prosperidad de la que hablaba el presidente del Consejo no había alcanzado a toda la población, pues a los niños más necesitados de la colonia «...ha habido que proveerles de la ropa más indispensable porque estaban francamente harapientos, importando

\footnotetext{
${ }^{134}$ Luis Cavanillas Ávila, «La Colonia Escolar de los Hijos de Obreros de Almadén», Diario Lanza (Ciudad Real), 21 de mayo de 1943, 4.
}

135 Hernández, Los reclusos mineros de Almadén..., 49-50. 
1.000 pesetas las alpargatas y vestidos y aun algunas sábanas».136 A mediados de la década de 1940, se creó también una colonia escolar en las instalaciones de la Escuela de Magisterio de Soria, donde los 30 niños y niñas más necesitados, en su mayoría huérfanos de mineros, disfrutaban de unos días de vacaciones. Esta colonia de altura continuaba existiendo diez años después, pues se trataba, al parecer, de un tratamiento preventivo de la tuberculosis, enfermedad siempre presente en los tiempos de hambre. ${ }^{137}$

En 1945 se estableció la Ley de Instrucción Primaria, que incidía en que la educación infantil debía tener un carácter confesional, patriótico, social, intelectual, físico y profesional. Tal y como dijo el ministro Ibáñez Martín en el discurso de presentación de dicha ley en las Cortes, la educación primaria se ponía al servicio de la religión y de la patria, con lo que entregaba las escuelas al control de la Iglesia católica. Esta revalidó así su posición dominante en la enseñanza, la cual se ajustaría «... a los principios del dogma y la moral católica, y a las disposiciones del derecho canónico vigente». ${ }^{138}$ La instrucción primaria se declaraba obligatoria y gratuita, con separación de sexos y comprendía desde los seis hasta los doce años, estableciéndose dos ciclos de enseñanza. En la escuela se prohibió cualquier lengua que no fuera el castellano y existía la obligación de que todas las aulas estuvieran presididas por un crucifijo y los retratos de Franco y José Antonio. ${ }^{139}$ Esta ley, junto a la depuración masiva de maestros llevada a cabo con anterioridad, sirvió para desmontar los aspectos de la reforma educativa de la República: coeducación, laicidad y pedagogía avanzada. ${ }^{140}$

No obstante, la política escolar del franquismo no invirtió partida alguna en nuevas escuelas hasta 1945 y a partir de entonces las

\footnotetext{
136 AHMA, ACA, 3 de mayo de 1944, 5-6.

137 Anónimo, «Clausura del curso en las Escuelas de Hijos de Obreros de Almadén. Colonia escolar», Diario Lanza (Ciudad Real), 13 de julio de 1949, 6.

${ }_{138}$ González, «Educación y dictadura franquista...», 1-2.

${ }_{139}$ En la prisión de Alcalá de Henares hubo un taller de carpintería, donde los reclusos fabricaron decenas de miles de crucifijos a cambio de redimir penas por el trabajo.

140 Borja de Riquer Permanyer, Historia de España, vol. IX. La dictadura de Franco (Barcelona: Crítica/Marcial Pons, 2013), 319.
} 
inversiones se hicieron con cuentagotas, gastos mucho menores que los realizados durante la Republica. Igual pasó con los maestros, como lo demuestra que ganaban menos comparativamente en 1941 que en 1913 (879 pesetas frente a 1.000), por lo que en la posguerra continuaba siendo válida la frase de "pasar más hambre que un maestro de escuela». En resumen, la escuela española en la posguerra siguió siendo «...escasa, pobre, abandonada de los poderes públicos, con unos maestros mal pagados y olvidados de la preocupación pública». ${ }^{141} \mathrm{La}$ consecuencia de esa política fue que todavía a finales de la década de 1950, un tercio de los niños permanecía marginado del sistema educativo. ${ }^{142}$

Los nuevos manuales escolares inculcaban a los alumnos un patriotismo exacerbado y una rígida moral católica, de modo que los niños españoles debían amar a Dios sobre todas las cosas y a la Virgen María, y además a la Patria y a su gloriosa bandera roja y gualda. La intención era clara: acostumbrar a niños y niñas a seguir los principios de jerarquía, disciplina y obediencia. Al mismo tiempo que se ponía grave énfasis en la familia como base de la sociedad cristiana, se establecía el papel subordinado de las mujeres, ya que su misión era la de esposas y madres, lo que las mantenía apartadas de cualquier actividad pública. Únicamente se les permitía jugar ciertos roles, como el de maestra y por ello el 70\% del alumnado de Magisterio era femenino.

Mientras tanto, la Escuela de Hijos de Obreros continuaba creciendo, de modo que en el curso 1945-1946 había 880 alumnos, distribuidos en 16 secciones, 7 de niños, 7 de niñas y 2 de párvulos. ${ }^{143}$ El comedor, el ropero y la colonia escolar tenían una dotación de 25.000 pesetas anuales, sufragadas 10.000 por el Ministerio y las restantes 15.000 por el Consejo. Las becas para que los mejores alumnos pudieran continuar sus estudios fuera de Almadén habían aumentado en número, pasando de seis en el curso 1942-1943 a diecisiete en 19451946 , con una dotación por alumno y mes de 500 pesetas. ${ }^{144}$ Lo que

\footnotetext{
141 Navarro, «El franquismo, la escuela y el maestro...», 169.

142 Riquer, Historia de España, vol. IX. La dictadura de Franco, 318.

${ }_{143}$ Escuela de Hijos de Obreros, Memoria del curso 1945-1946, 13.

${ }_{144}$ Escuela de Hijos de Obreros, Memoria del curso 1945-1946, 14-15.
} 
continuaba invariable era «... el triple lema de Dios, religión y Patria». ${ }^{145}$

La docencia en Almadén se extendía a la enseñanza media en la Academia Lope de Vega, en la que estudiaban casi un centenar de alumnos, de los cuales casi la mitad eran hijos de mineros ${ }^{146}$. También había clases para adultos analfabetos, pues en octubre de 1942 todavía el 25\% de los adultos de Almadén no sabía leer ni escribir. Por su parte, el Consejo de Administración aceptó la propuesta del director de la mina para que las clases de adultos fueran obligatorias para los jóvenes aspirantes a lograr un puesto de trabajo en el establecimiento minero, así como para aquellos mineros que quisieran ascender de nivel en el escalafón. En el curso de 1942 a 1943, 400 obreros menores de treinta años asistieron obligatoriamente a la clase de adultos ${ }^{147}$ y en el curso de 19451946 hubo $180 .{ }^{148}$

A principios de la década de 1950, la cotización internacional del mercurio se duplicó, de modo que un frasco pasó de valer 100 a 200 dólares. ${ }^{149}$ Además se encontraron nuevas aplicaciones de este metal para la industria, como las centrales térmicas ${ }^{150}$ y las baterías secas. Terminaba por entonces el aislamiento internacional de España y aunque nuestro país no fue incluido en el plan Marshall, el presidente Truman concedió a Franco un préstamo de 62 millones de dólares en 1950 para modernizar el armamento del Ejército español en plena guerra fría. A mediados de la década de los cincuenta del siglo XX, el mercurio había vuelto a ser un negocio muy rentable para la Hacienda española con la

\footnotetext{
145 Escuela de Hijos de Obreros, Memoria del curso 1945-1946, 4.

${ }_{146}$ Los exámenes oficiales de los siete cursos se hacían en Ciudad Real y el examen de Estado en la calle San Bernardo de Madrid, sede de la Universidad Central (comunicación personal de Horacio Serrano, alumno de dicha Academia).

147 Escuela de Hijos de Obreros, Memoria del curso 1942-1943, 18.

148 Escuela de Hijos de Obreros, Memoria del curso 1945-1946, 18.

149 La inestabilidad global provocada por la guerra de Corea provocó el aumento del precio de las materias primas y, entre ellas, los metales, tal y como había sucedido con anterioridad en las dos guerras mundiales.

150 En ellas, el mercurio sustituía al agua, renovándose así las antiguas centrales de vapor y ampliando notablemente la potencia instalada, sin necesidad de aumentar el caudal del agua en sus circuitos de refrigeración.
} 
consiguiente entrada de divisas en el Tesoro Público. ${ }^{151}$ La firma del Concordato con la Santa Sede en 1953 supuso para la Iglesia Católica, además de un conjunto de privilegios y beneficios jurídicos y económicos, el triunfo de su ideario en el ámbito educativo: la confesionalidad de todos los tipos de enseñanza, el control e inspección sobre ellos, la obligatoriedad de la religión como asignatura en todos los niveles educativos y la suficiencia de los grados mayores eclesiásticos para el ejercicio de la docencia. ${ }^{152}$

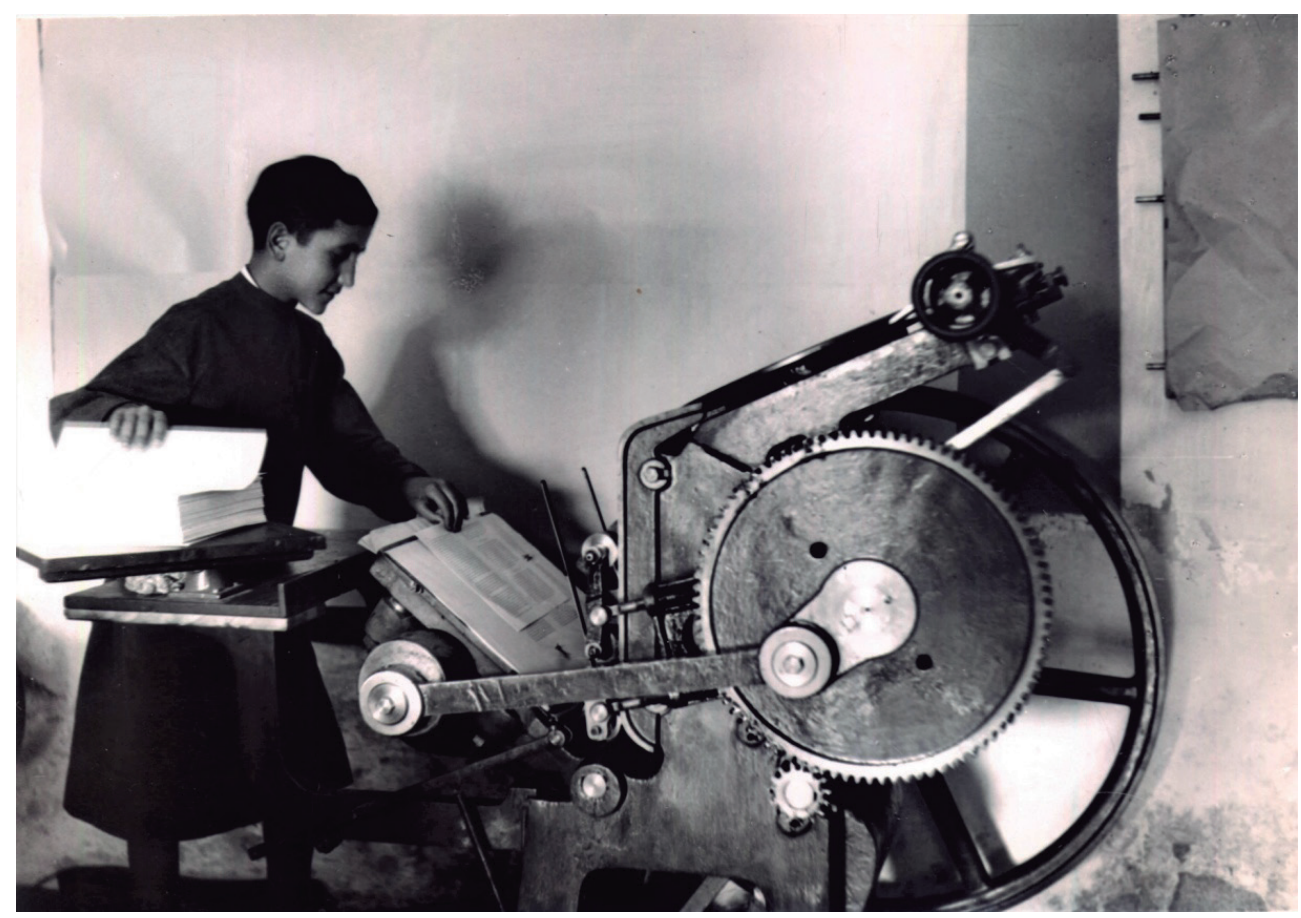

Imagen 6. Aprendiz de impresor hacia 1944. Fuente: AHN, FC-MA, Fondo fotográfico, n. ${ }^{\circ} 101$

Por entonces, en la Escuela de Hijos de Obreros a la doctrina católica se le seguía uniendo el ideario franquista, pues «... es una organización escolar enmarcada en los moldes y postulados de nuestra Cruzada, es una ciudad infantil viviente, en donde bajo los pliegues amorosos

151 Hernández, Los mineros del azogue, 456.

152 Viñao, Escuela para todos..., 70. 
de las banderas nacional y del Movimiento, izadas diariamente en respetuoso silencio y en posición de firme, se enseña a servir y amar a esta patria única que es España. Es una colmena infantil formada por varios centenares de pequeñuelos que rezan pidiendo a Dios diariamente por su patria y su Caudillo». ${ }^{153}$ La Enciclopedia Álvarez, con sus tres volúmenes adaptados a la edad de los alumnos, era el libro más caracterizado y en ella se trataban temas relacionados con historia sagrada, lengua española, aritmética, historia, geografía, ciencias naturales, formación política, etc. A esta enciclopedia se añadían las cartillas para que los más pequeños aprendieran a leer, escribir y dibujar, y también los cuadernos pedagógicos, adaptados a cada una de las asignaturas. ${ }^{154}$

En cuanto a la enseñanza media, muchos estudiantes tuvieron como profesores de Lengua, Historia u otras asignaturas a frailes y monjas sin los adecuados conocimientos, quienes se dedicaban solamente a tomar la lección a sus alumnos. Los manuales escolares de la década de los cincuenta eran claramente continuistas respecto de los del primer franquismo, si bien «... los adjetivos que se utilizan para definir a los republicanos adquieren tonos menos descalificadores, aunque persistan en su condena genérica del significado destructivo y antiespañol de la política republicana en su conjunto». ${ }^{155}$ En uno de estos manuales se relata así la época de la II República y Guerra Civil:

La Constitución de 1931 fue esencialmente democrática, laica y socializante [...]. Tras las elecciones de febrero de 1936 el camino hacia la Guerra Civil fue facilitado por la actitud revolucionaria adoptada por el jefe socialista Largo Caballero [...]. España quedó dividida en dos zonas. Así dio comienzo una cruenta Guerra Civil de tres años, en la que las fuerzas del Movimiento Nacional casi nunca abandonaron la iniciativa. 156

\footnotetext{
153 Escuela de Hijos de Obreros, Memoria del curso 1955-1956, 1.

154 Gallego-Preciados, Colegio Hijos de Obreros de Almadén..., 46-47.

155 Rafael Valls Montés, Historia y memoria escolar. Segunda República, Guerra Civil y dictadura franquista en las aulas (Valencia: Publicaciones de la Universidad de Valencia, 2009), 44-45.

156 Jaime Vicens Vives y Santiago Sobrequés, Ágora. Historia Universal y de España. Edades Moderna y Contemporánea (Barcelona: Editorial Teide, 1957), 185-190.
} 
En suma, un tratamiento casi exclusivamente político y con escasas referencias al contexto social, económico y cultural.

Pese a las dificultades económicas de la década de 1940, la tasa de alfabetización mejoró considerablemente en España. En lo que a la provincia de Ciudad Real se refiere, el 52,3\% de los hombres y el 59,2\% de las mujeres eran analfabetos en 1940, porcentajes que se habían reducido al 17,79\% y al 33, 88\%, respectivamente. ${ }^{157}$ La favorable situación económica de Minas de Almadén debido al aumento de la cotización internacional del mercurio en los primeros años de la década de 1950 repercutió en la Escuela de Hijos de Obreros, la cual incrementó considerablemente su alumnado y, en consecuencia, su profesorado. Si a principios de la década de 1940 había 12 maestros para unos 600 alumnos, a mediados de los cincuenta los alumnos eran más de 1.100 y 25 los maestros, si bien la relación media de alumnos por maestro solo había descendido de 50 a 44. Además, había siete profesores auxiliares para los talleres de artesanía y 11 subalternos, quienes atendían el día a día de la Escuela. Para albergar tanta actividad educativa se construyó en 1955 un nuevo edificio, cuyo coste total fue de 2.350.000 pesetas, incluyendo el mobiliario escolar. ${ }^{158}$ En 1956, el ropero escolar proporcionaba ropa por valor de 13.000 pesetas anuales a treinta alumnos, mientras que treinta y seis usaban el comedor, que tenía un presupuesto anual de 24.000 pesetas. ${ }^{159}$ Todavía en abril de 1959, el Consejo seguía prestando ayuda al servicio escolar de alimentación de la Escuela, lo que le agradecía el Ministerio de Educación. ${ }^{160}$

\section{CONCLUSIONES}

A finales del siglo XIX y principios del XX, las grandes empresas mineras e industriales españolas pusieron en marcha procedimientos generalizados de prácticas paternalistas. Entre ellas estaban las viviendas obreras, los economatos, las iglesias y también las escuelas. Los patronos, fueran privados o públicos, como fue el caso de Almadén, intervenían en la vida y no solo en el trabajo de los operarios. Nacía así el paternalismo industrial,

\footnotetext{
157 «La provincia de Ciudad Real en los años 40», Lanza Digital, 21 de mayo de 2019.

158 Gallego-Preciados, Colegio Hijos de Obreros de Almadén..., 53.

159 Escuela de Hijos de Obreros, Memoria del curso escolar 1955-1956, 7.

160 AHMA, ACA, 1 de abril de 1959, 3.
} 
un programa estratégico para intentar impedir la separación entre vida y trabajo, dicho de otro modo, entre existencia privada y vida pública.

El caso de Almadén es algo especial, ya que su mina de mercurio venía explotándose desde siglos atrás y, por tanto, no había surgido al socaire de la revolución industrial. Por otro lado, su lejanía geográfica de otros centros productivos y sus malas comunicaciones aislaban a Almadén y convertían al establecimiento minero en un monopolio de trabajo para los vecinos del pueblo. Por ello, las viviendas obreras no fueron construidas hasta mediados del siglo $\mathrm{XX}$, ya que los mineros vivían desde siempre distribuidos por la localidad.

En conclusión, las grandes empresas, sobre todo del norte de España, eligieron a finales del XIX y principios del XX la educación religiosa como la más adecuada para la instrucción de los hijos de sus operarios. En Almadén ocurrió lo mismo, pues aunque no se trataba de una empresa minera privada sino dependiente del Ministerio de Hacienda, se fundó en 1908 la Escuela de Obreros Adultos y de Hijos de Obreros, dotándola de un alto contenido religioso. En 1926, el Consejo de Administración, creado en 1918, optó por convertir dicha escuela en avemariana, siguiendo por tanto la pedagogía del padre Manjón. Convertida en escuela laica durante los años de la República y guerra civil, en 1939 volvió a convertirse en escuela manjoniana, si bien con un fuerte matiz patriótico. A partir de entonces, el Consejo procuró que los niños, buena parte de los cuales se convertirían en futuros trabajadores del establecimiento minero, recibieran como pilares educativos un conjunto de preceptos que les harían obreros cultos, honrados y laboriosos, pero también religiosos y patrióticos, mientras que las niñas se convertirían en esposas y madres modelo, pilares de hogares cristianos en los que resplandecería el orden, la economía y la higiene.

\section{Notas sobre los autores}

Emiliano Almansa Rodríguez es Profesor Titular de Escuela Universitaria en la Escuela de Ingeniería Minera e Industrial de Almadén (Universidad de Castilla-La Mancha) y Doctor por la Universidad de Córdoba. Su último capítulo de libro es "The dehesa of Castilseras and the mines of Almadén in 19 century». En Current and Future Trends in Mercury 
Research, editado por Pablo León Higueras, Javier de las Morenas, Francisco Mata, y Francisco José Sáez-Martínez, 1-12. Oxford: Chartridge Books, 2018. Sus últimos artículos publicados son «Spanish engineers and scientists serving at the service of the Almadén quicksilver mines in the second half of the XVIII century», Dyna 93, n. ${ }^{\circ} 4$ (2018): 380-384; «Almadén en la España del siglo XVII. Crisis de producción de azogue y soluciones propuestas», Vínculos de Historia 8 (2019): 337-353; y «Las minas de mercurio de Almadén 1939 a 1960. Estrategias de producción, modernización y su repercusión en los obreros y la población» Historia Contemporánea, 62, 119-157, 2020.

Ángel Hernández Sobrino es Licenciado en Ciencias Geológicas por la Universidad Complutense de Madrid. Doctor en Geología por la Universidad de Salamanca. Profesor de Geología de la Escuela Universitaria Politécnica de Almadén (Universidad Politécnica de Madrid). Gerente de la Fundación Almadén- Francisco Javier de Villegas. Jubilado en 2012. Su trayectoria investigadora está relacionada fundamentalmente con la historia y el patrimonio minero de Almadén. Sus libros más relevantes son: Las minas de Almadén (1995, reeditado en 2000). Los mineros del azogue (2007). Los esclavos del rey. Los forzados de Su Majestad en las minas de Almadén, años 1550-1800 (2010). Los reclusos mineros de Almadén (2012). Entre la espada y la pared. Los jornaleros del campo de Ciudad Real en la posguerra (2020). Sus últimos artículos publicados son: "Almadén en la España del siglo XVII. Crisis de producción de azogue y soluciones propuestas», Vínculos de Historia 8 (2019): 337-353 y «Las minas de mercurio de Almadén 1939 a 1960. Estrategias de producción, modernización y su repercusión en los obreros y la población», Historia Contemporánea 62 (2020): 119-57.

\section{REFERENCIAS}

Alía Miranda, Francisco. Ciudad Real durante la dictadura de Primo de Rivera. Instituto de Estudios Manchegos, 1986.

Arce, Victorino de. «Manjón, educador». Pulso 25 (2002): 87-101.

Asensio Rubio, Francisco. La enseñanza primaria. Ciudad Real: II República y

Guerra civil. Ciudad Real: Excma. Diputación Provincial de Ciudad Real, 2007. 
Canes Garrido, Francisco. «Las Escuelas del Ave María: una institución renovadora de finales del siglo XIX en España». Revista Complutense de Educación 10, n. ${ }^{\circ} 2$ (1999): 149-166. http://revistas.ucm.es/index.php/RCED/article/ view/RCED9999220149A/17151.

Fernández Soria, Juan Manuel. «Desmemoria de la educación republicana en el franquismo». En Entre el olvido y la memoria. Educación, mitos y realidades, editado por Teresa González Pérez, 73-106. Valencia: Tirant Humanidades, 2018.

Gallego-Preciados Algora, Ana Isabel (coord.). Colegio Hijos de Obreros de Almadén. La huella de un Siglo. Albacete: Gráficas Campollano, 2008.

García Arenal, Fernando. Datos para el estudio de la cuestión social. Gijón: Imprenta del comercio, 1885.

García Cárcel, Ricardo. La herencia del pasado. Las memorias históricas de España. Barcelona: Galaxia Gutenberg, 2011.

García López, María Esther y Miguel Arbizu Senosiaín. «La escuela manjoniana del Ave María de Arnao. Su pasado: un siglo de historia». En Actas del XIV Congreso de la SEDPGYM, compilador por José María Mata Perelló, 670. Manresa: SEDPGYM, 2014.

González Madrid, Damián Alberto. «Educación y dictadura franquista. Los años cuarenta». En La educación en Castilla-La Mancha en el siglo XX, dirigido por María del Mar del Pozo, 1-27. Ciudad Real: Biblioteca Añil, 2007. https://previa.uclm.es/AB/humanidades/seft/pdf/textos/damian/educacion.pdf.

Hernández Sobrino, Ángel. Los mineros del azogue. Ciudad Real: Fundación Almadén-Francisco Javier de Villegas, 2007.

Hernández Sobrino, Ángel. Los reclusos mineros de Almadén, 1940-1944. Ciudad Real: Fundación Almadén-Francisco Javier de Villegas, 2012.

Iniesta Corredor, Alfonso. Garra marxista en la infancia. Burgos: Hijos de Santiago Rodríguez, 1939.

Madoz, Pascual. Diccionario geográfico-estadístico-histórico de España y sus posesiones de ultramar, 1845-1850. Madrid: Ámbito Editorial, 1987.

Manjón Manjón, Andrés. Discurso leído en la solemne apertura del Curso Académico 1897-1898 en la Universidad Literaria de Granada. Granada: Imprenta-Escuela del Ave María, 1905.

Manjón Manjón, Andrés. Hojas circunstanciales, hojas históricas y hojas cronológicas del Ave María. Madrid: Gráficas Nebrija, 1956.

Mansilla Plaza, Luis y Ana Isabel Gallego-Preciados Algora. «El trabajo infantil en las Minas de Almadén desde el siglo XVIII hasta 1939». En II Congreso Nacional Ciudad Real y su provincia, 534-549. Ciudad Real: Instituto de Estudios Manchegos, 2016.

Marín y Rodríguez, Desiderio. Almadén y sus obreros. Ciudad Real: Establecimiento tipográfico de Enrique Pérez, 1906. 
Martín, Francisco de Luis y Luis Arias González. 75 años con la enseñanza. FETE-UGT (1931-2006). Madrid: Federación de Trabajadores de la Enseñanza de UGT, 2006.

Navarro Saladrinas, Ramón. "El franquismo, la escuela y el maestro (19361975)». Historia de la Educación 8 (1989):167-180. http://campus.usal. es/ revistas_trabajo/index.php/02120267/article/viewFile/6832/6818.

Navarro Saladrinas, Ramón. La enseñanza primaria durante el franquismo (1936-1975). Barcelona: Promociones y Publicaciones Universitarias, 1990.

Nevares, Sisinio. El patrono ejemplar. Una obra maestra de la acción social. Madrid: Editorial Razón y Fe, 1936.

Pérez de Perceval, Miguel Ángel y Andrés Sánchez Picón. «El trabajo infantil en la minería española, 1850-1940»s. En VIII Congreso de la Asociación Española de Historia Económica,1-20. Santiago de Compostela, 2005. https://www. aehe.es/wp-content/uploads/2005/10/a1_perez_perceval_sanchez_picon.pdf

Pericacho Gómez, Francisco Javier. «Pasado y presente de la renovación pedagógica de España (de finales del Siglo XIX a nuestros días). Un recorrido a través de escuelas emblemáticas». Revista Complutense de Educación 25, n. ${ }^{\circ}$ 1 (2014): 47-67. http://dx.doi.org/10.5209/rev_RCED.2014.v25.n1.43309.

Pontes y Fernández, José María. Historia de la antigua ciudad de Sisapón (hoy Almadén del Azogue). Madrid: Imprenta de Enrique Rojas, 1900.

Ramos Zamora, Sara. La depuración del magisterio de primera enseñanza en Castilla-La Mancha (1936-1945). Madrid: Universidad Complutense, 2004.

Riquer Permanyer, Borja de. Historia de España, vol. 9. La dictadura de Franco. Barcelona: Crítica/Marcial Pons, 2013.

Valls Montés, Rafael. Historia y memoria escolar. Segunda República, Guerra Civil y dictadura franquista en las aulas. Valencia: Publicaciones de la Universidad de Valencia, 2009.

Vicens Vives, Jaime y Santiago Sobrequés. Ágora. Historia Universal y de España. Edades Moderna y Contemporánea. Barcelona: Editorial Teide, 1957.

Villares, Ramón y Javier Moreno Luzón. Historia de España, vol. 7, Restauración y dictadura. Barcelona: Crítica/Marcial Pons, 2009.

Viñao Frago, Antonio. Escuela para todos. Educación y modernidad en la España del siglo XX. Madrid: Marcial Pons Historia, 2004.

Zarraluqui Martínez, Julio. Los almadenes de azogue. La historia frente a la tradición. Madrid: Librería Internacional de Romo, 1934. 